\title{
Ultrastructural analysis of neuroimplant-parenchyma interfaces uncover remarkable neuroregeneration along-with barriers that limit the implant electrophysiological functions
}

Running title: Ultrastructure of neuroimplant-parenchyma interfaces

Aviv Sharon ${ }^{1,2}$, Nava Shmoel ${ }^{1,3}$, Hadas Erez ${ }^{1,2}$, Maciej M. Jankowski ${ }^{2,4}$, Yael Friedmann ${ }^{5}$, and Micha E. Spira ${ }^{1,2,3^{*}}$

${ }^{1}$ Department of Neurobiology, the Alexander Silberman Institute of Life Science, The Hebrew University of Jerusalem, Jerusalem, Israel

${ }^{2}$ The Charles E. Smith Family and Prof. Joel Elkes Laboratory for Collaborative Research in Psychobiology, the Hebrew University of Jerusalem, Jerusalem, Israel

${ }^{3}$ The Harvey M. Kruger Family Center for Nanoscience, the Hebrew University of Jerusalem, Jerusalem, Israel

${ }^{4}$ Edmond and Lily Safra Center for Brain Sciences, the Hebrew University of Jerusalem, Jerusalem, Israel

${ }^{5}$ Bio-Imaging Unit, The Alexander Silberman Institute of Life Science the Hebrew University of Jerusalem, Jerusalem, Israel

*Corresponding author: Micha E. Spira spira@cc.huji.ac.il.

Keywords: neural-engineering, neuro-electronics, neuro-implant, interfacing, microelectrodes, ultrastructure, immunohistology, polyimide

Number of words: 5919

Number of figures and tables: 8 figures, 8 supplementary figures and two tables

\begin{abstract}
Despite increasing use of in-vivo multielectrode array (MEA) implants for basic research and medical applications, the critical structural interfaces formed between the implants and the brain parenchyma, remain elusive. Prevailing view assumes that formation of multicellular inflammatory encapsulating-scar around the implants (the foreign body response) degrades the implant electrophysiological functions. Using gold mushroom shaped microelectrodes (gM $\mu E s)$ based perforated polyimide MEA platforms (PPMPs) that in contrast to standard probes can be thin sectioned along with the interfacing parenchyma; we examined here for the first time the interfaces formed between brains parenchyma and implanted 3D vertical microelectrode platforms at the ultrastructural level. Our study demonstrates remarkable regenerative processes including neuritogenesis, axon myelination, synapse formation and capillaries regrowth in contact and around the implant. In parallel, we document that individual microglia adhere tightly and engulf the gM $\mu$ Es. Modeling of the formed microgliaelectrode junctions suggest that this configuration suffice to account for the low and deteriorating recording qualities of in vivo MEA implants. These observations help define the anticipated hurdles to adapting the advantageous 3D in-vitro vertical-electrode technologies to in-vivo settings, and suggest that improving the recording qualities and durability of planar or $3 \mathrm{D}$ in-vivo electrode implants will require developing approaches to eliminate the insulating microglia junctions.
\end{abstract}




\section{Introduction}

Basic and clinically oriented brain research and their applications rely on the use of sophisticated neuro-implants for long-term, simultaneous, multisite extracellular recordings of field potentials (FP) generated by neurons in freely behaving subjects. Despite significant technological progress, contemporary in-vivo multielectrode array (MEA) technologies suffer from inherent limitations that include: (a) a low signal-to-noise ratio $(\mathrm{S} / \mathrm{N})$, (b) low source resolution and (c) deterioration of the recording yield and FP amplitudes within days to weeks of implantation (Jackson and Fetz, 2007;Perge et al., 2013;Voigts et al., 2013; Harris et al., 2016;Lee et al., 2018;Lee et al., 2021). In addition, current in-vivo brain implants are "blind" to sub-threshold synaptic potentials generated by individual neurons. This implies that critical elements of the brains signaling repertoire and computational components are ignored. The prevailing view relates these limitations to: (a) the gradual increase in the thickness of the inflammatory glia scar that displaces neurons from the implant surfaces (Edell et al., 1992; Biran et al., 2005;Polikov et al., 2005;Malaga et al., 2016;Salatino et al., 2017a;Michelson et al., 2018), (b) the glial scar encapsulating the implant (Szarowski et al., 2003;Johnson et al., 2005;Polikov et al., 2005;Otto et al., 2006;Williams et al., 2007;Prasad and Sanchez, 2012) and a biofouling layer assembled on the electrode surfaces insulate the electrodes from the current sources by their relatively high resistivity compared to the intact brain tissue (Sommakia et al., 2009;Sommakia et al., 2014;Malaga et al., 2016), (c) pro-inflammatory cytokines released from the glia and injured neurons lead to demyelination of the axons and thereby disrupt action potential propagation (Winslow et al., 2010; Winslow and Tresco, 2010), (d) released cytokines reduce the excitability and synaptic connectivity of neurons in the implant's vicinity (Vezzani and Viviani, 2015;Salatino et al., 2017b;Hermann and Capadona, 2018; Salatino et al., 2019; Thompson et al., 2020), (e) damage to blood capillaries by the implant leads to infiltration of neurotoxic factors and myeloid cells (Saxena et al., 2013) and reduces the blood supply to individual cells. Although objective experimental attempts to relate the thickness of the inflammatory foreign body response (FBR) to deterioration in recording qualities have failed, this concept has continued to dominate the field and still shapes extensive research efforts to mitigate or overcome this deterioration. Whereas ever-improving spike-detecting, spike-sorting and signal averaging techniques make it possible to extract significant information from monitoring extracellular FP (Quiroga et al., 2004;Einevoll et al., 2012;Carlson and Carin, 2019), the limited recording qualities of current multielectrode array-implants (MEA implants) and their deterioration in time considerably hinder the research progress.

The realization that the use of substrate integrated planar MEA technologies for extracellular recordings (Figure 1) inherently limits the qualities of in-vitro and in-vivo systems has prompted the development of new 3D in-vitro technologies to enable parallel, multisite intracellular recordings and stimulation from many individual cultured cells (neurons, cardiomyocytes and striated muscles). In principle, this family of in-vitro MEA technologies utilizes different forms of 3D vertical nano-structures (nano-pillars) that pierce the plasma membrane of cultured cells (by electroporation or spontaneously) in a way similar to classical sharp electrodes (Figure 1 and Tian et al., 2010;Angle and Schaefer, 2012;Duan et al., 2012; Gao et al., 2012;Robinson et al., 2012;Xie et al., 2012;Angle et al., 2014;Lin and Cui, 2014; Lin et al., 2014; Qing et al., 2014;Abbott et al., 2017;Dipalo et al., 2017; Liu et al., 2017; Abbott et al., 2018;Abbott et al., 2019;Mateus et al., 2019; Li et al., 2020;Teixeira et al., 2020; Yoo et al., 2020; Xu et al., 2021;Zhang et al., 2021).

At the same time, a number of laboratories have developed the "IN-CELL" recording and stimulation configuration, in which micrometer-sized, extracellular gold mushroom-shaped microelectrodes $(\mathrm{gM \mu Es})$ record attenuated synaptic and action potentials (Figure 1 and Spira et al., 2007;Hai et al., 2010b;a;Fendyur and Spira, 2012;Spira and Hai, 2013;Rabieh et al., 
2016;Shmoel et al., 2016;Weidlich et al., 2017;McGuire et al., 2018;Spira et al., 2018;Mateus et al., 2019; Spira et al., 2019;Jones et al., 2020;Teixeira et al., 2020). Ultrastructural imaging complemented by electrophysiology and model system analysis of the culturedneurons $/ \mathrm{gM} \mu$ Es configuration have revealed that the biophysical principles of "IN-CELL" recordings are identical to those of the perforated patch electrode configuration (Horn and Marty, 1988;Akaike and Harata, 1994).

Successful adaptation of the vertical nano-pillar and gM $\mu$ Es MEA approaches to in-vivo brain research could effectively address the limitations of the currently used planar MEA technologies (low $\mathrm{S} / \mathrm{N}$, poor source resolution and deterioration), and importantly would make it possible to record the entire signaling repertoire from many individual neurons. It is thus expected that such adaptation will significantly improve the likelihood of understanding the codes of brain-circuit computations.

Ultrastructural examinations of the interfaces formed between cultured neurons and gM $\mu \mathrm{Es}$ or vertical nano-pillar based MEAs have played key roles in revealing that cultured neurons and other cell types tightly engulf vertical structures by evolutionarily conserved cell biological mechanisms (Hai et al., 2010b;Santoro et al., 2014;Santoro et al., 2017b;McGuire et al., 2018). And, that the narrow cleft formed between the engulfing plasma membrane and the $\mathrm{gM} \mu \mathrm{Es}$ form a high seal resistance (Rs). This, together with the increased conductance of the cell's membrane that faces the gM $\mu$ Es (the junctional membrane - Rj, Figure 1), make it possible to record attenuated action potentials and subthreshold synaptic potentials with features and biophysics similar to perforated patch recordings (Horn and Marty, 1988;Akaike and Harata, 1994;Spira et al., 2007;Hai et al., 2009a;Hai et al., 2009b;Fendyur et al., 2011;Santoro et al., 2013; Santoro et al., 2014;Santoro et al., 2017a;Santoro et al., 2017b).

In contrast to meticulous ultrastructural studies of the interfaces formed between cultured cells and different types of vertical nanoelectrodes, structural studies of the interfaces formed between implanted neuroprobes and in-vivo brain parenchyma were of very low resolution. Besides the inherent low spatial resolution of the immunohistological methods used, in the vast majority of light and electron microscope studies, the implants were pulled out (extracted) from the brain tissue prior to thin sectioning for histological examination. This unavoidably damages the parenchyma/implant interfaces, making it impossible to examine and understand the structural relationships between the abiotic implant and the tissue (for example Schultz and Willey, 1976;Moss et al., 2004;Grand et al., 2010;Marton et al., 2020).

Using $\mathrm{gM} \mu \mathrm{Es}$ based perforated polyimide MEA platforms that can be thin sectioned along with the interfacing parenchyma; we examined here for the first time the interfaces formed between brains parenchyma and implanted 3D vertical microelectrode ( $\mathrm{gM} \mu \mathrm{Es})$ platforms at the ultrastructural level. Our study demonstrates remarkable structural parenchyma regenerative processes including neuritogenesis, axon myelination and synapse formation in contact and around the implant. In parallel, we documented that individual microglia adhere tightly and engulf the $\mathrm{gM} \mu \mathrm{E}$ electrodes. The extracellular cleft formed between the implant and the adhering microglia in parallel to the microglia's input resistance suggest that high resistance barriers are formed in contact with the electrodes. We posit that these microgliaelectrode-junctions, rather than the thick multicellular inflammatory encapsulation that is thought to displace neuronal cell bodies and induce axon demyelination or structural synapse degeneration, are the underlying mechanisms governing the deterioration of the electrical coupling between neurons and the in-vivo implanted electrodes. In addition, our ultrastructural observations objectively highlight the expected hurdles to applying arrays of vertical nano-pillars in general and $\mathrm{gM} \mu \mathrm{Es}$ in particular to record intracellular potentials from cortical neurons in freely behaving rats. Approaches to mitigate or selectively eliminate the adhering microglia are thus needed to advance the application of 3D microelectrode arrays for intracellular recording of the entire signaling repertoire of the in-vivo brain. 


\section{Materials and Methods Animals}

All the procedures in the present study were approved by the Committee for Animal Experimentation at the Institute of Life Sciences of the Hebrew University of Jerusalem. This study was conducted using female Sprague Dawley rats (215-340 g).

\section{Neuro-implants}

To address the technical features required to prepare thin sections of implanted $\mathrm{gM} \mu \mathrm{E}-$ platforms along with the parenchyma around it, we fabricated nonfunctional implants constructed of a Perforated Polyimide (PI)-based MEA Platform (PPMP) that carries a dense array of gold mushroom shaped microelectrodes (gM $\mu \mathrm{E}$, Figure 1). The $1.7 \mathrm{~mm}$ long, $280 \mu \mathrm{m}$ wide and $16 \mu \mathrm{m}$ thick nonfunctional gM $\mathrm{gE}$-PPMPs were divided to a $0.9 \mathrm{~mm}$ long solid proximal part and a $0.8 \mathrm{~mm}$ perforated distal part (Figure 1). The perforated segment tapered to form a sharp tip. The width of all the rectangular perforations was 7-8 $\mu \mathrm{m}$ and the lengths of the different perforations were 65,47 and $44 \mu \mathrm{m}$ (Figure 1). gM $\mu$ Es were electroplated at a pitch of $8 \mu \mathrm{m}$ in rows along the 15 gold conducting lines that run along the platform (Figure 1 and Supplementary Figure S1).

\section{Implant fabrication}

The gM $\mu$ E-PPMPs were constructed using standard photolithography fabrication methods as follows (Supplementary Figure S1). First, an aluminum releasing layer was sputtered on a 3inch silicon wafer (University Wafer, USA), followed by a spin-coated $15 \mu \mathrm{m}$ thick polyimide layer (PI 2610, HD Microsystems, Germany) that served as an insulating layer and the main mechanical backbone of the platform. A triple metal layer of $\mathrm{Cr} / \mathrm{Au} / \mathrm{Cr}(20 / 120 / 20$ $\mathrm{nm}$ ) was then patterned and e-beam evaporated as interconnects, pads and scribe-lines. Next, a second $1 \mu \mathrm{m}$ thick insulating layer of polyimide was spin-coated, followed by the deposition of a $1 \mu \mathrm{m} \mathrm{SiO} \mathrm{Si}_{2}$ with Plasma Enhanced Chemical Vapor Deposition (PECVD). A $1.5 \mu \mathrm{m}$ photoresist layer was then patterned. Dry etching by RIE was used to define $1.5 \mu \mathrm{m}$ molds for electroplating the $\mathrm{gM} \mu \mathrm{Es}$ and pads through the $\mathrm{SiO}_{2}$ and the one micrometer thick insulating PI layer. After removal of the top Cr layer by wet etch, gM $\mu$ Es with cap diameters of $\sim 2 \mu \mathrm{m}$ were electrodeposited at a pitch of $8 \mu \mathrm{m}$ along the tip and a perforated section of the platform (Figure 1 and Supplementary Figure S1). An additional $300 \mathrm{~nm}$ of $\mathrm{SiO}_{2}$ was deposited with PECVD and a photoresist layer were used to define the perforated pattern of the platform. The photoresist and $\mathrm{SiO} 2$ layers were then removed and the platforms were then released from the wafer by anodic metal dissolution and thoroughly rinsed in distilled deionized water.

\section{Platform implantations}

A 1-1.5 cm longitudinal cut of the skin on the head was made and the anterior, dorsal surfaces of the skull were exposed. Two craniotomies, one in the left and the other in the right frontal bones, were performed at the desired reference points (coordinates: AP: $+3.5 \mathrm{~mm}$; ML: +2.5 $\mathrm{mm}$ from the Bregma) and the dura was gently resected (0.3-0.5 mm long incision). The 1.7 $\mathrm{mm}$ long platforms held by forceps mounted on a micromanipulator were slowly inserted into the motor cortex to a depth of $1.8 \mathrm{~mm}$. The electrodes were gently released from the holder and the craniotomy was sealed with melted bone wax (W810, Ethicon, Belgium). The wound was treated in situ with antibiotic ointment (Synthomycine, chloramphenicol 5\%) and sutured with nylon sutures. Then the rats received an intraperitoneal injection of the antibiotic Enrofloxacin $50 \mathrm{mg} / \mathrm{ml}(5 \% \mathrm{~W} / \mathrm{V})$ at a dose of $15 \mathrm{mg} / \mathrm{kg}$ diluted with saline to $1 \mathrm{ml}$ (Baytril, Bayer Animal Health $\mathrm{GmbH}$, Leverkusen, Germany). In line with standard protocols to prevent postoperative pain, the rats received for three consecutive days after gM $\mu$ E-PPMP implantation non-steroidal anti-inflammatory/analgesic drugs. A subcutaneous injection of Carprofen $50 \mathrm{mg} / \mathrm{ml} \mathrm{(5 \%} \mathrm{W/V)} \mathrm{in} \mathrm{a} \mathrm{dose} \mathrm{of} \mathrm{about} 12 \mathrm{mg} / \mathrm{kg}$ (Norocarp, Norbrook Laboratories Limited, Newry, Co. Down, Northern Ireland) during surgery. To further reduce the stress and pain caused by injections and prevent mechanical stress to the skin around the 
bioRxiv preprint doi: https://doi.org/10.1101/2021.10.03.461535; this version posted October 4, 2021. The copyright holder for this preprint

implantation site, the rats were fed on days 2 and 3 post PPMP implantation by Meloxicam (Rheumocam, oral suspension $1.5 \mathrm{mg} / \mathrm{ml}$, Chanelle pharma) dissolved in palatable Jelly. To that end, Meloxicam dissolved in agar (Meloxicam-jelly) prepared in a small Petri dish (diameter of $35 \mathrm{~mm}$ ) was placed in the rat cages. The Petri dishes were removed at the end of days 2 and 3. Visual checks confirmed that the rats consumed the entire volume of the Meloxicam-jelly. After surgery, the animals were housed individually to prevent them from chewing the implants.

\section{Tissue processing for immunohistology and transmission electron microscopy}

For brain tissue fixation, individual rats were deeply anesthetized with isoflurane (Piramal, United States) followed by an IP overdose injection of pentobarbital $(4.5 \mathrm{ml}$ per $250 \mathrm{~g}$ rat, CTS Group, Israel). When breathing had stopped, the rats were transcardially perfused with phosphate buffer saline (PBS). This was followed by a 4\% paraformaldehyde in PBS (PFA, Sigma-Aldrich) perfusion for immunohistology and $1-2.5 \%$ glutaraldehyde/2\% paraformaldehyde (Agar Scientific) for transmission electron microscopy (TEM). In both cases, the perfusion rate was $10 \mathrm{ml} / \mathrm{min}$ and lasted for $40 \mathrm{~min}$. Next, the skulls were removed and the implanted brains were post-fixed at $4^{\circ} \mathrm{C}$ for an additional $12-24 \mathrm{hrs}$. in either PFA (for immunohistology), or glutaraldehyde/paraformaldehyde (for TEM). Thereafter, the fixed and exposed brains destined for immunohistology were washed in PBS and incubated for 1-3 days in a $30 \%$ sucrose solution in PBS at $4^{\circ} \mathrm{C}$.

To prepare the brain tissue for cryosectioning (immunohistology), cubic shaped portions of tissue (approximately $1 \times 1 \times 1 \mathrm{~cm}$ ) with the PPMP in their center were isolated. The isolated piece was placed in a freezing medium (Tissue- Plus O.C.T. Compound, Scigen) and frozen at $-80^{\circ} \mathrm{C}$. The frozen tissues along with the implanted platform were then horizontally sectioned into $40 \mu \mathrm{m}$ thick slices using a Leica CM1850 Cryostat. Individual slices were collected and placed in 24 well plates containing PBS. The tissue slices were then incubated in blocking solution (1xPBS, $1 \%$ heat-inactivated horse serum (Biological Industries), $0.1 \%$ Triton X-100 (Sigma Aldrich)) for 1 hour at room temperature (RT) under gentle shaking. Next, the slices were incubated with a diluted primary antibody for 3 hours at room temperature (RT) and washed 3 times with the blocking solution. This was followed by 1-hour incubation at RT with the diluted secondary antibody after which the slices were washed with the blocking solution 3 times and stained with the nuclear marker DAPI (Sigma-Aldrich, $1 \mathrm{mg} / \mathrm{ml} \mathrm{1:1000)}$ for 15 min at RT. After washing with the blocking solution and PBS, the slices were mounted on Superfrost Plus Slides (Thermo Fisher Scientific) and sealed by a Vectashield (VE-H-1000 -Vector Labs) mounting medium.

\section{Electron microscopy}

For TEM imaging, glutaraldehyde/paraformaldehyde fixed tissue along with the PI, MEA platform implants were washed with PBS and sliced by a Leica VT1000S Vibrotome using a ceramic blade (Campden Instruments Ltd.) into $200 \mu \mathrm{m}$ thick horizontal sections. The slices were deposited in 24 well plates with PBS.

After 8 washes with $0.1 \mathrm{M}$ cacodylate buffer at $\mathrm{pH} 7.4$ (SigmaAldrich) the tissue was post fixed by $1 \%$ osmium tetroxide (Electron Microscopy Sciences) and $0.6 \% \mathrm{~K} 3 \mathrm{Fe}(\mathrm{CN})_{6}$ in a $0.1 \mathrm{M}$ cacodylate buffer for $1 \mathrm{hr}$. at room temperature. The slices were then washed again in a $0.1 \mathrm{M}$ cacodylate buffer and dehydrated by a series of increasing concentrations of ethanol solutions of $10 \%, 25 \%, 50 \%, 75 \%, 90 \%, 96 \%, 100 \%, 100 \%$. Finally, the slices were embedded in Agar 100 (Agar Scientific). The embedded preparation was then thin-sectioned and observed using a TEM Tecnai 12 microscope at $100 \mathrm{kV}$. The shown TEM images were taken from sections prepared across the perforated part of the implant (rows 2-6 as marked in Figure 1). Efforts were made to orientate the thin sections perpendicular to the long axis of

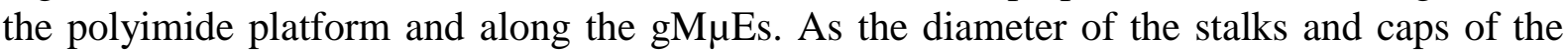
$\mathrm{gM} \mu \mathrm{Es}$ are in the range of $1-3 \mu \mathrm{m}$, a slight deviation from a perfect sectioning angle, resulted 
in imperfect sections that did not pass through the entire length of the $\mathrm{gM} \mu \mathrm{E}$ cap and stalk. Thus, in some cases, the sections went through the entire length of the mushrooms cap, stalks and the contact between the stalk and the conducting line (for example Figures 6 and 7A). In others, the thin sections were slightly tilted in respect to the long axis of the gM $\mu \mathrm{E}$ stalks. In these cases the stalk of the mushroom appears to taper toward the polyimide platform. The observed TEM images and conclusions represent transmission electron microscope imaging of over > 250 thin sections prepared from 25 different PPMPs implants.

\section{Immunolabeling, confocal imaging, image processing, analysis and statistics}

Immunolabeling, imaging, image processing and analysis were conducted as detailed in previous studies from our laboratory (Huang et al., 2020; Sharon et al., 2021). Briefly, neurons were concomitantly labelled with two antibodies: one for neurite labelling (mouse antiNeurofilament 160/200 monoclonal antibody (Sigma-Aldrich N2912, 1:10000-1:20000) and the other for neuronal nuclei (mouse anti-NeuN monoclonal antibody (Merck MAB377, 1:200)). Astrocytes were labelled with chicken anti-glial fibrillary acidic protein (GFAP) polyclonal antibodies (Thermo Fisher PA1-10004, 1:500-1000). Microglia were labelled using rabbit anti-Iba-1 monoclonal antibody (Abcam ab178846, 1:1000). For the secondary antibodies we used goat anti-mouse Alexa 488, goat anti-chicken Alexa 647 (Thermo Fisher A-11001 and A21449 respectively, 1:100) and sheep anti-rabbit Cy3 (Sigma-Aldrich C2306, $1: 100)$.

Confocal image stacks of the immunolabeled slices were acquired with an Olympus FLUOVIEW FV3000 confocal scan head coupled to an IX83 inverted microscope, using a $20 \mathrm{X}$ air objective $(\mathrm{NA}=0.75)$. Typically, 15-30 confocal slices were acquired, with a vertical spacing of $1 \mu \mathrm{m}$. Image processing of the immunolabeled sections was conducted using the Fiji distribution of ImageJ (Schindelin et al., 2012;Schneider et al., 2012).

Two methods of analysis and representation of the cell densities in contact and around the PPMPs were used: (1) The densities of the astrocytes and neurons, including their cell bodies and neurites, were analyzed and displayed as the relative fluorescent intensities with respect to the normal background. These are referred to in Figure 2 E2 and E3 as the Normalized Fluorescent Intensity (NFI) values (Huang et al., 2020). (2) The density of the microglia and neuronal cell bodies per $100 \mu \mathrm{m}^{2}$, at a given shell around the implant, and within the pores were calculated by manual counting (Figure $2 \mathrm{E} 1$ and E4). The counting of these cell bodies was done by merging Ibal labelled microglia or NeuN labeled neurons with the nuclear marker DAPI.

Average fluorescent values and cell counting characterizing the FBR in space and time were measured and calculated from cortical brain slices prepared from sections from across rows 5-8 within the $280 \mu \mathrm{m}$ wide, perforated part of the implant (Figures $1 \mathrm{~B}$ and 2). We used 2-10 hemispheres/experimental points in time (Supplementary Table 1). Each brain hemisphere was used to prepare 1 to 6 tissue slices. Each slice was used to prepare a single maximal projected image generated by 10 consecutive optical sections. For more data on the numerical values and statistical tests, see Supplementary Table 2.

\section{Results}

\section{Probe design principles}

To address the technical features required to prepare thin sections of implanted $\mathrm{gM \mu E}$ platforms along with the parenchyma around it, we fabricated nonfunctional implants constructed of a Perforated Polyimide (PI)-based MEA Platform (PPMP) that carries a dense array of gold mushroom shaped microelectrodes (gM $\mu$ E-PPMP, Figure 1). PI was selected because it is a biocompatible polymer with a Young's modulus of 2.5 GP. Importantly, based on studies demonstrating that PI implants can be thin-sectioned for histological examinations (Mercanzini et al., 2007;Mercanzini et al., 2008;Richter et al., 2013;Xie et al., 2014;Boehler 
et al., 2017;Huang et al., 2020) our laboratory has developed procedures to section implanted $\mathrm{gM} \mu \mathrm{E}-\mathrm{PPMPs}$ along with the surrounding brain parenchyma for light and transmission electron-microscope (TEM) studies (Huang et al., 2020;Sharon et al., 2021). In the present study, we fabricated $1.7 \mathrm{~mm}$ long, $280 \mu \mathrm{m}$ wide and $16 \mu \mathrm{m}$ thick nonfunctional $\mathrm{gM} \mu \mathrm{E}-$ PPMPs. The proximal $0.9 \mathrm{~mm}$ of the implant was constructed of solid PI, and the remaining distal part was perforated (Figure 1). The perforated segment tapered to form a sharp tip. The width of all the rectangular perforations was 7-8 $\mu \mathrm{m}$ and the lengths of the different perforations were 65, 47 and $44 \mu \mathrm{m}$ (Figure 1). gM $\mu$ Es were electroplated in rows along the conducing gold lines which run in between the perforations (Supplementary Figure S1). The high density of the gM $\mu$ Es served to increase the probability of successfully preparing thin sections $(80 \mathrm{~nm})$ for TEM imaging through $\mathrm{gM} \mu$ Es and PI along with the interfacing brain parenchyma. The perforated microarchitecture of the platform reduced the projected solid surface area of the perforated part by $35 \%$ and allowed cells to extend branches or migrate through the perforations. Each pore in the PI platform approximately doubled the PI surface to which the cells could adhere.

\section{Ultrastructure of the implant and parenchyma}

To examine the interfaces formed between the brain parenchyma and implanted $\mathrm{gM} \mu \mathrm{E}-$ PPMPs, cross-sections for transmission electron microscopy of gM $\mu$ E-PPMPs along with the surrounding tissue were prepared. We selected to examine the ultrastructure of the inflammatory scar at two, four and eight weeks after electrode implantation, since our earlier immunohistological studies showed characteristic alterations in the distribution and densities of the microglia, astrocytes and neurons at these points in time (Figure 2 and Huang et al., 2020; Sharon et al., 2021). For the reader's convenience, the overall spatiotemporal relationships between microglia, astrocytes, neurons and PPMP implants is briefly presented in Figure 2 using conventional immunohistological imaging.

For the ultrastructural analysis, gM $\mu$ E-PPMP implanted brains were chemically fixed by standard transcardial perfusion of glutaraldehyde/paraformaldehyde fixative. Since MEA platform implantation unavoidably damages blood capillaries along the insertion path, concern was raised whether the quality of tissue fixation around the implant will suffice to preserve the tissue ultrastructure. In retrospect, based on the preservation qualities of the cell membranes and subcellular organelles including the mitochondria, the smooth and rough endoplasmic reticulum, synaptic vesicles, post-synaptic densities and myelin, we concluded that the perfusion of the fixative was not impaired in the surroundings of the implant. It is important to note, however, that as in other ultrastructural studies of the CNS, the extracellular spaces between the various cell types is reduced by approximately $20 \%$ (Korogod et al., 2015;Hrabetova et al., 2018; Soria et al., 2020). Since the volume of the implanted PPMPs is not altered by the fixatives, transcardial fixation led to the generation of mechanical tension around the implant. This often tears the tissue around the implant. Importantly, tissue growing into the PPMP pores and adhering to the platform surfaces remained tightly attached to the platforms, and the break in the tissue took place between cells or even across cells a few micrometers away from the implant surface.

Since the relative positioning of the PPMP and the cells around it are not altered by the classical method of transcardial fixative perfusion, the TEM analysis presented here suffices to provide the essential and missing information on implant brain-tissue interfaces. In addition, because the range of the shrinkage factor is known, the genuine extracellular clefts can be estimated. It is important to note that TEM examination of hundreds of thin sections representing over $25 \mathrm{gM} \mu \mathrm{E}-\mathrm{PPMP}$ implants revealed that the $\mathrm{gM} \mu \mathrm{Es}$ maintain stable contact with the conducting lines used for their electroplating. That is, the $\mathrm{gM} \mu \mathrm{Es}$ are not striped off during the platforms insertion or during the thin sectioning of the tissue along with the implant for TEM imaging. 
bioRxiv preprint doi: https://doi.org/10.1101/2021.10.03.461535; this version posted October 4,2021 . The copyright holder for this preprint

Insulation of the PPMP implants by microglia at two weeks post PPMP implantation Typically, at two weeks post gM $\mu$ E-PPMPs implantation, tightly adhering dark cytoplasmic microglia processes (dark as compared to other cell profiles in their surroundings) encapsulated individual PI "ribs" (Figures 3 and 4). The cell bodies from which the dark cytoplasm emanated contained characteristic microglia nuclei with clumps of heterochromatin beneath the nuclear envelope and throughout their nucleoplasm (Figure 3 and see Tremblay et al., 2012;Garcia-Cabezas et al., 2016;Savage et al., 2018;Nahirney and Tremblay, 2021). The electron-dense cytoplasm of these microglia was bordered by a clear plasma membrane and contained rough endoplasmic reticulum, mitochondria and dark inclusions which may plausibly be lysosomes and lipofuscin granules (Figures 3 and 4).

In line with Figure 2 and our earlier immunohistological studies (Huang et al 2020; Sharon et al 2021), two weeks post-PPMP implantation, TEM images revealed the presence of astrocyte cell bodies and branches in close proximity to the platform surface and within the platform pores (Figures 3B and 4A). Astrocyte cell bodies could be identified by their pale nuclei that had a thin rim of heterochromatin and pale cytoplasm (Figures 3 and 4A). Typically, the cytoplasm of astrocyte branches are characterized by sparse electron- dense material containing intermediate filaments (glial fibrillary acidic protein, GFAP, Garcia-Cabezas et al., 2016; Nahirney and Tremblay, 2021).

Two weeks after implantation, the dark microglia cytoplasm that adheres tightly to the $\mathrm{gM \mu E}-$ PPMPs surfaces are often interposed between the PPMP surfaces and the astrocytic branches, thus mechanically preventing direct contact between the neurite and astrocytic branches and the platform surfaces (Figure 3B).

Immunohistological imaging of the neurite revealed that at two weeks post-implantation, neurites extended into the PI platform pores (Figures 2C and E3). Based on the presence of microtubules in axons and GFAP in astrocytes (Figure 3B) it was possible to differentiate between the branches of the astrocytes and the unmyelinated neurites (axons and dendrites). At two weeks post-PPMP implantation, no myelinated axonal profiles were observed in the immediate vicinity $(<10 \mu \mathrm{m})$ to the gM $\mu$ E-PPMPs. Further away from the implants $(>10 \mu \mathrm{m})$ myelinated axons were observed (Figure 3).

Neuronal cell bodies characterized by typical round euchromatic nuclei, the presence of electron dense nucleoli and nuclear membrane invaginations were observed as close as $\sim 20$ $\mu \mathrm{m}$ from the PI platform and onwards (see also Figure 2 E4). Chemical presynaptic terminals identified by the presence of profiles containing clusters of synaptic vesicles or chemical synapses identified by presynaptic fibers in association with typical post-synaptic densities were imaged at a distances of approximately $10 \mu \mathrm{m}$ from the platform.

\section{Regenerative processes in contact and around PPMP implants at four weeks post- PPMP implantation}

Immunohistological examination of the changes in cell composition and distribution within and around the implanted PPMPs 4 weeks after PPMP implantation (Figure 2) suggested that the parenchyma around the implant had undergone regenerative processes. These included: (a) a reduction in the average microglia density in the first shells around the implant, but not within the PPMP pores (Figure 2 E1 and Huang et al., 2020); (b) a significant increase in the average density of the neuronal cell bodies in the first shell around the implant, preceded by the extension of neurites towards the implant and into the PPMP pores (Figure 2 E3\&E4 and Huang et al., 2020). In contrast to these regenerative processes, the astrocyte branches and cell bodies continued to increase during the fourth week post- implantation both within the PPMPs and in the first shell around it (Figure 2 E2).

The overall regenerative processes observed at the confocal microscope resolution were reflected and more finely delineated at the ultrastructural levels. TEM images revealed myelinated axons extending towards and in the vicinity of the implant surface (Figure 5). A 
considerable increase in the density of structurally mature chemical synapses was seen. At 4 weeks post-implantation, the PPMP's "ribs" were no longer enwrapped by dark protoplasmic protrusions emanating from microglia cell bodies. Rather, relatively thin layers of electron opaque cytoplasm adhered to the surface of the PPMPs and the gM $\mu$ Es (Figure 5). Relevant to the electrophysiological recording functions of the implant (see discussion), it is noted that the extracellular cleft formed between the microglia membranes that enwrapped the $\mathrm{gM} \mu \mathrm{E}$ remained in the range of 10-20 nm (Figure 5B). The microglia clearly interposed between the myelinated axons extending in the electrodes' vicinity and between pale cytoplasmic profiles of astrocytic branches and unmyelinated axons. Astrocyte branches and cell bodies, microglia and unmyelinated axonal profiles were seen occupy the pores between the PI "ribs" and directly adhere to the PI surfaces.

In addition, large profiles of dark cytoplasm containing phagocytosed materials were occasionally observed to reside within the pores (Supplementary Figure S5). In a few cases, the section went through the nucleus of these large cells. Based on the heterochromatin distribution of the nucleus, these cells were likely to be microglia. These cell types were never observed outside the PI implant pores.

In summary, whereas clear regeneration of the neuron cell body densities, axons, dendrites and synapses took place within the first shell around the implant, dark microglia branches adhering to the gM $\mu E s$ and PPMPs were still present. These adhering microglia can be assumed to electrically insulate the electrodes from the surrounding neurons (see discussion).

\section{Increased density of neurons near the implant surface eight weeks post-PPMP implantation}

Confocal microscope imaging of the cortical parenchyma interfaced 8 weeks after PPMP implantation revealed that the overall regenerative processes that were observed 2 to 4 weeks after implantation persisted. (a) The microglia density within the implant was further reduced to half of its peak value and to a third in the first shell around the implant (Figure $2 \mathrm{E} 1$ and Huang et al 2020). (b) Whereas the neurite density (NFI values, Figure 2 E3) did not change, the average neuronal cell body density in the first shell around the implant further increased to $86 \%$ with respect to the control level (Figure 2 E4). (c) On the other hand, the astrocyte (branches and cell bodies together) continued to increase mainly in the first shell around the implant (Figure 2 E2). These regenerative trends were reflected at the TEM level, in particular in that neuronal cell bodies were imaged to reside as close as $\sim 2 \mu \mathrm{m}$ from the gM $\mu \mathrm{E}$ caps (Figures 6 and 7A). The narrow space between the cell bodies membrane and the gM $\mu \mathrm{E}$ caps were occupied by small profiles (with a diameter in the range of $<1 \mu \mathrm{m}$ ) of either astrocytes or neurites. Parts of the gM $\mathrm{gE}$ stalk and caps were enwrapped by narrow $(\sim 100 \mathrm{~nm})$ dark cytoplasmic protrusions probably corresponding to microglia branches, while other parts appeared to be free of microglia. Myelinated axonal profiles were observed to form a direct contact with $\mathrm{gM} \mu \mathrm{E}$ caps (Figure 7B). Chemical synaptic profiles were observed as close as $\sim 0.5 \mu \mathrm{m}$ to the PI platform and the $\mathrm{gM \mu Es}$, and within the parenchyma surrounding the implant. The pores within the PI platform were mainly occupied by astrocytic branches and unmyelinated axonal profiles. No synaptic structures were observed within the pores.

TEM observations conducted 8 weeks after the PPMP implantation, occasionally revealed $\mathrm{gM} \mu \mathrm{E}$ that were not insulated by microglia. Under these conditions, the $\mathrm{gM} \mu \mathrm{Es}$ formed a direct contact with many small $(\sim 100 \mathrm{~nm})$ axonal or astrocytic profiles (Figure $7 \mathrm{D})$. It is conceivable that the small surface area of these tentatively identified unmyelinated axonal profiles were too small to generate sufficient current to be measured by the $\mathrm{gM \mu E}$ system.

\section{Discussion}

Despite significant progress, contemporary in-vivo MEA technologies suffer from inherent limitations that include a low signal-to-noise ratio, low source resolution and deterioration of 
the recording yield and FP amplitudes within days to weeks of implantation. Whereas these drawbacks constitute a critical impediment to the progress of basic and clinically oriented brain research, the mechanisms that generate these limitations remain elusive. For that reason, attempts to develop effective methods to overcome these drawbacks have only been marginally successful.

To achieve a better understanding of the mechanisms that limit the functions of implanted electrophysiological neuroprobes, for the first time, the present study examined the intact ultrastructural interfaces formed between the cortical parenchyma and a large footprint implanted neuroprobes. The findings reveal remarkable tissue regeneration around and in contact with the large-footprint implanted MEA platform. This include the regrowth of neurites towards the implant, myelination of the newly grown axons, the formation of structurally mature chemical synapses, the recovery of neuronal cell body densities in the vicinity of the electrodes (at a distance of $\sim 1 \mu \mathrm{m}$ from the electrodes' surfaces) and cortical capillaries (Figure 8). Along with this remarkable tissue regeneration, we documented that individual microglia adhering to the gM $\mu$ Es-PPMP surfaces formed a micrometer-thin barrier in contact with the PI backbone and the gM $\mu$ Es which we dub the "microglia-insulatingjunction". For a period of approximately 8 weeks post-PPMP implantation (the longest observation period made here), the adhering microglia prevented the formation of a direct contact between the axons or neuronal cell bodies and the $\mathrm{gM} \mu \mathrm{E}$. Thus, engulfment of $\mathrm{gM} \mu \mathrm{Es}$ and most likely other 3D or planar microelectrodes by neurons is likely to be impeded. Because the microglia insulating junctions are formed at the electrode surfaces, this configuration offers an explanation to the enigma as to why no correlation has been found between the dimensions and density of the FBR and recording qualities (Kozai et al., 2014;Kozai et al., 2015;McCreery et al., 2016;Du et al., 2017;Salatino et al., 2017a;Michelson et al., 2018).

Ultrastructural analysis of the junctions formed between different cell types and planar or 3D microelectrodes under in-vitro conditions have served a pivotal role in deciphering the biophysics and potential applications of the junctions formed. An order of magnitude estimate of microglia- $\mathrm{gM \mu E}$-junction impedance can be derived using a passive electrical circuit model composed of two parallel resistors: the seal resistance $\left(\mathrm{R}_{\mathrm{s}}\right)$ formed by the cleft between the plasma membrane of the microglia and the surface of the $\mathrm{gM \mu Es}$, and the input resistance $\left(\mathrm{R}_{\mu \mathrm{g}}\right)$ of the adhering microglia.

The seal resistance $\left(R_{s}\right)$ is given by $R_{\text {seal }}=\rho_{s} \cdot \delta / d$, where $\rho_{s}$ is the resistivity of the electrolyte solution $\left(\rho_{\mathrm{s}}=0.7 \Omega \mathrm{Cm}\right), \mathrm{d}$ is the average cleft width between the neuron's plasma membrane and the electrodes' surface, and $\delta$ is the overlapping surface coefficient that takes into account the percentage of the electrodes' sensitive area in contact with the microglia (Massobrio et al., 2016). Because of the unavoidable $20 \%$ shrinking artifact of the extracellular spaces due to the chemical fixation of the tissue for TEM imaging (Korogod et al., 2015;Hrabetova et al., 2018; Soria et al., 2020) the actual width (d) of the clefts formed between the microglia and the implanted gM $\mathrm{gEs}$-PPMPs surfaces cannot be extracted with precision from the ultrastructural images. In addition, the fraction of the surface area of the contact between a $\mathrm{gM} \mu \mathrm{E}$ or planar electrode and the adhering microglia $(\delta)$ cannot be obtained from classical TEM images. Nonetheless, an order of magnitude estimate of $\mathrm{R}_{\mathrm{s}}$ formed by different cell types can be obtained by using parameters published previously in the literature. A large number of in-vitro studies have revealed that the cleft width formed between different cultured cell types and artificial substrates ranges from 20 to $100 \mathrm{~nm}$ (Braun and Fromherz, 1998;Iwanaga et al., 2001; Straub et al., 2001;Lambacher and Fromherz, 2002;Brittinger and Fromherz, 2005;Gleixner and Fromherz, 2006;Wrobel et al., 2008) and the contact surface area of these junctions has been estimated. The estimated seal resistance derived in these studies ranged from $\sim 1 \mathrm{M} \Omega$ in the case of planar electrodes (Weis and Fromherz, 
1997;Buitenweg et al., 1998;Buitenweg et al., 2002) to 40-100 M $\Omega$ s for gM $\mu$ Es (Hai et al., 2009a;Fendyur et al., 2011;Spira and Hai, 2013;Ojovan et al., 2015;Shmoel et al., 2016; Massobrio et al., 2018; Spira et al., 2019).

The input resistance of mice microglia $\left(\mathrm{R}_{\mu \mathrm{g}}\right)$ was reported to be 2-5 G $\Omega$ (Avignone et al., 2008; Schilling and Eder, 2015). Since the morphology and physiology of microglia are known to change under different functional states and in response to different substrates (Eder, 1998;2005;2010;Kettenmann et al., 2011), it is conceivable that the input resistance of microglia adhering to the $\mathrm{gM} \mu \mathrm{Es}$ is less than 2-5 G $\Omega$. Assuming that the input resistance of adhering microglia is reduced to the range of 10-100 $\mathrm{M} \Omega$, the resistance formed by an adhering "microglia insulating junction" is in the range of $\sim 1 \mathrm{M} \Omega$ for a planar electrode and $\sim 50 \mathrm{M} \Omega \mathrm{s}$ for a $\mathrm{gM} \mu \mathrm{E}$ or a vertical nano-pillar engulfed by a microglia $\left(\mathrm{R}_{\mu \mathrm{g}} \cdot \mathrm{R}_{\mathrm{s}} / \mathrm{R}_{\mu \mathrm{g}}+\mathrm{R}_{\mathrm{s} .}\right)$.

Given that the estimated resistance of intact brain parenchyma is in the range of 1-4 $\Omega$ (Logothetis et al., 2007), and 300-6000 $\Omega$, across an encapsulation glial scar (Turner et al., 1999;Szarowski et al., 2003;Moffitt and McIntyre, 2005;Grill and Mortimer, 2014), the current generated by neurons positioned very close or in contact with microglia adhering to a sensing electrode is expected to be attenuated by 1-3 orders of magnitude. Thus, the FPs generated by neurons positioned in the immediate vicinity of a microglia-insulating-junction might be below the level of detection.

It is worth noting that recent progress in bioengineering has led to the implementation of ultra-small and ultra-flexible platforms, with dimensions comparable to those of a single neuron (Xiang et al., 2014;Fu et al., 2016;Luan et al., 2017;Zhao et al., 2017;Wei et al., 2018;Guan et al., 2019; Yang et al., 2019;Zhang et al., 2021). Immunohistological observations have shown that these ultra-small, flexible implants integrate seamlessly with brain tissue, and that under these conditions neuronal cell bodies are seen to reside in close proximity to the implant (Fu et al., 2016;Luan et al., 2017;Zhou et al., 2017;Hong et al., 2018; Yang et al., 2019). Despite the fact that the impedances of these ultra- small and ultraflexible electrodes are similar to those of conventional implants $(0.5-1 \mathrm{M} \Omega)$ and despite the seamless integration of these platforms with brain tissue, the recorded amplitudes of the FP have been within the range of those recorded by implants that trigger FBR. These observations are inconsistent with the prevailing hypothesis that in the absence of a histological FBR the FPs amplitudes should be larger. This apparent paradox may be resolved by assuming that even if a "classical" FBR is not imaged as having been formed by these implants, microglia insulating-junctions that were not detected by standard immunohistology nevertheless formed and insulated the electrodes.

Overall, the present study resolves two critical questions: (1) what are the cellular mechanisms that underlie the limited electrophysiological functions of implanted in-vivo neuroprobes and (2), can the successfully developed and advantageous gM $\mu \mathrm{E}$ or other 3D vertical nano-pillars be applied to in-vivo settings? We posited that the insulation formed by individual microglia that tightly adhere to or engulf in-vivo implanted electrodes rather than multicellular FBR deteriorate the electrical coupling coefficient between the neurons and the implanted electrodes. The microglia electrode junctions structurally isolate and electrically insulate the electrodes from the neurons and hence limit the electrophysiological functions of the electrodes. Overcoming the challenging microglia insulating-junction requires developing new protocols to specifically and temporally target the adhering microglia. This should be complemented by methods to increase the density of neuronal cell bodies to enable the formation of direct contact with the electrodes.

It is conceivable that the effective structural regeneration of the parenchyma in the immediate vicinity of the gM $\mu \mathrm{E}-\mathrm{PPMP}$ implants and the implant-parenchyma integration documented here reflect compound abiotic and biotic factors. For that reason, it is premature to extrapolate the observation made here to implants composed of different materials, with different 
microarchitecture, sizes and shapes, and implanted in different brain regions in different organisms.

\section{Conflicts of interest}

The authors declare that the research was conducted in the absence of any commercial or financial relationships that could be construed as a potential conflict of interest.

\section{Author Contributions}

A.S. implanted the platforms and processed the tissues for both immunohistological and transmission electron microscope sectioning together with H.E.. A.S. and H.E. analyzed the images. N.S. headed the fabrication of the perforated polyimide MEA platforms. M.M. J. supervised the PPMP implantations. Y.F. thin sectioned the tissues for TEM imaging and helped with the analysis. M.E.S. conceived, designed, and supervised the project.

\section{Funding}

This work was supported by the Israel Science Foundation grant number 1808/19. Part of this work was conducted at the Charles E. Smith and Prof. Joel Elkes Laboratory for Collaborative Research in Psychobiology. This study is based on an earlier research project supported by the National Institute of Neurological Disorders and Stroke of the National Institutes of Health under Award Number U01NS099687.

\section{Acknowledgment}

We thank Drs. Shimon Eliav, Galina Chechelinsky, Maurice Saidian, Evgenia Blayvas from the Harvey M. Kruger Family Center for Nanoscience for taking part in the fabrication of the perforated polyimide-based MEA platforms. The content is solely the responsibility of the authors and does not necessarily represent any official views of the granting agencies.

\section{References}

Abbott, J., Ye, T., Ham, D., and Park, H. (2018). Optimizing Nanoelectrode Arrays for Scalable Intracellular Electrophysiology. Acc. Chem. Res. 51, 600-608.

Abbott, J., Ye, T., Krenek, K., Gertner, R.S., Ban, S., Kim, Y., Qin, L., Wu, W., Park, H., and Ham, D. (2019). A nanoelectrode array for obtaining intracellular recordings from thousands of connected neurons. Nat Biomed Eng.

Abbott, J., Ye, T., Qin, L., Jorgolli, M., Gertner, R.S., Ham, D., and Park, H. (2017). CMOS nanoelectrode array for all-electrical intracellular electrophysiological imaging. Nat Nanotechnol $12,460-466$.

Akaike, N., and Harata, N. (1994). Nystatin perforated patch recording and its applications to analyses of intracellular mechanisms. Jpn J Physiol 44, 433-473.

Angle, M.R., and Schaefer, A.T. (2012). Neuronal recordings with solid-conductor intracellular nanoelectrodes (SCINEs). PLoS One 7, e43194.

Angle, M.R., Wang, A., Thomas, A., Schaefer, A.T., and Melosh, N.A. (2014). Penetration of cell membranes and synthetic lipid bilayers by nanoprobes. Biophys $J$ 107, 2091-2100.

Avignone, E., Ulmann, L., Levavasseur, F., Rassendren, F., and Audinat, E. (2008). Status epilepticus induces a particular microglial activation state characterized by enhanced purinergic signaling. $J$ Neurosci 2.9133-9144,8

Biran, R., Martin, D.C., and Tresco, P.A. (2005). Neuronal cell loss accompanies the brain tissue response to chronically implanted silicon microelectrode arrays. Exp Neurol 195, 115-126.

Boehler, C., Kleber, C., Martini, N., Xie, Y., Dryg ,I., Stieglitz, T., Hofmann, U.G., and Asplund, M. (2017). Actively controlled release of Dexamethasone from neural microelectrodes in a chronic in vivo study. Biomaterials 129, 176-187.

Braun, D., and Fromherz, P. (1998). Fluorescence interferometry of neuronal cell adhesion on microstructured silicon. Phys Rev Lett 81, 5241-5244. 
bioRxiv preprint doi: https://doi.org/10.1101/2021.10.03.461535; this version posted October 4,2021 . The copyright holder for this preprint (which was not certified by peer review) is the author/funder, who has granted bioRxiv a license to display the preprint in perpetuity. It is made available under aCC-BY-NC-ND 4.0 International license.

Brittinger, M., and Fromherz, P. (2005). Field-effect transistor with recombinant potassium channels: fast and slow response by electrical and chemical interactions. Applied Physics a-Materials Science \& Processing 81, 439-447.

Buitenweg, J.R., Rutten, W.L., Marani, E., Polman, S.K., and Ursum, J. (2002). Extracellular detection of active membrane currents in the neuron-electrode interface. J Neurosci Methods 115, 211-221.

Buitenweg, J.R., Rutten, W.L., Willems, W.P., and Van Nieuwkasteele, J.W. (1998). Measurement of sealing resistance of cell-electrode interfaces in neuronal cultures using impedance spectroscopy. Med Biol Eng Comput 36, 630-637.

Carlson, D., and Carin, L. (201 .(9Continuing progress of spike sorting in the era of big data. Curr Opin Neurobiol 55, 90-96.

Dipalo, M., Amin, H., Lovato, L., Moia, F., Caprettini, V., Messina, G.C., Tantussi, F., Berdondini, L., and De Angelis, F. (2017). Intracellular and Extracellular Recording of Spontaneous Action Potentials in Mammalian Neurons and Cardiac Cells with 3D Plasmonic Nanoelectrodes. Nano Lett 17, 3932-3939.

Du, Z.J., Kolarcik, C.L., Kozai, T.D.Y., Luebben, S.D., Sapp, S.A., Zheng, X.S., Nabity, J.A., and Cui, X.T .(2017) .Ultrasoft microwire neural electrodes improve chronic tissue integration. Acta Biomater 53, 46-58.

Duan, X., Gao, R., Xie, P., Cohen-Karni, T., Qing, Q., Choe, H.S., Tian, B., Jiang, X., and Lieber, C.M. (2012). Intracellular recordings of action potentials by an extracellular nanoscale field-effect transistor. Nature nanotechnology 7, 174-179.

Edell, D.J., Toi, V.V., Mcneil, V.M., and Clark, L.D. (1992). Factors influencing the biocompatibility of insertable silicon microshafts in cerebral cortex .IEEE Trans Biomed Eng 39, 635-643.

Eder, C. (1998). Ion channels in microglia (brain macrophages). Am J Physiol 275, C327-342.

Eder, C. (2005). Regulation of microglial behavior by ion channel activity. J Neurosci Res 81, 314321.

Eder, C. (2010). Ion channels in monocytes and microglia/brain macrophages: promising therapeutic targets for neurological diseases. J Neuroimmunol 224, 51-55.

Einevoll, G.T., Franke, F., Hagen, E., Pouzat, C., and Harris, K.D. (2012). Towards reliable spiketrain recordings from thousands of neurons with multielectrodes. Curr Opin Neurobiol 22, 11-17.

Fendyur, A., Mazurski, N., Shappir, J., and Spira, M.E. (2011). Formation of Essential Ultrastructural Interface between Cultured Hippocampal Cells and Gold Mushroom-Shaped MEA -Toward "INCELL" Recordings from Vertebrate Neurons. Front Neuroeng 4, 14.

Fendyur, A., and Spira, M.E. (2012). Toward on-chip, in-cell recordings from cultured cardiomyocytes by arrays of gold mushroom-shaped microelectrodes. Front Neuroeng 5, 21.

Fu, T.M., Hong, G., Zhou, T., Schuhmann, T.G., Viveros, R.D., and Lieber, C.M. (2016). Stable longterm chronic brain mapping at the single-neuron level. Nat Methods 13, 875-882.

Gao, R., Strehle, S., Tian, B., Cohen-Karni, T., Xie, P., Duan, X., Qing, Q., and Lieber, C.M. (2012). Outside looking in: nanotube transistor intracellular sensors. Nano letters 12, 3329-3333.

Garcia-Cabezas, M.A., John, Y.J., Barbas, H., and Zikopoulos, B. (2016). Distinction of Neurons, Glia and Endothelial Cells in the Cerebral Cortex: An Algorithm Based on Cytological Features. Front Neuroanat 10, 107.

Gleixner, R., and Fromherz, P. (2006). The extracellular electrical resistivity in cell adhesion. Biophys $J$ 90, 2600-2611.

Grand, L., Wittner, L., Herwik, S., Gothelid, E., Ruther ,P., Oscarsson, S., Neves, H., Dombovari, B., Csercsa, R., Karmos, G., and Ulbert, I. (2010). Short and long term biocompatibility of NeuroProbes silicon probes. Journal of Neuroscience Methods 189, 216-229.

Grill, W.M., and Mortimer, J.T. (2014). Electrical Properties of Implant Encapsulation Tissue. Ann Biomed Eng 22, 23-33.

Guan, S., Wang, J., Gu, X., Zhao, Y., Hou, R., Fan, H., Zou, L., Gao, L., Du, M., Li, C., and Fang, Y. (2019). Elastocapillary self-assembled neurotassels for stable neural activity recordings. $S c i A d v$, eaav2842.

Hai, A., Dormann, A., Shappir, J., Yitzchaik, S., Bartic, C., Borghs, G., Langedijk, J.P., and Spira, M.E. (2009a). Spine-shaped gold protrusions improve the adherence and electrical coupling of neurons with the surface of micro-electronic devices. J R Soc Interface 6, 1153-1165. 
bioRxiv preprint doi: https://doi.org/10.1101/2021.10.03.461535; this version posted October 4,2021 . The copyright holder for this preprint (which was not certified by peer review) is the author/funder, who has granted bioRxiv a license to display the preprint in perpetuity. It is made available under aCC-BY-NC-ND 4.0 International license.

Hai, A., Kamber, D., Malkinson, G., Erez, H., Mazurski, N., Shappir, J., and Spira, M.E. (2009b). Changing gears from chemical adhesion of cells to flat substrata toward engulfment of microprotrusions by active mechanisms. J Neural Eng 6, 066009.

Hai, A., Shappir, J., and Spira, M.E. (2010a). In-cell recordings by extracellular microelectrodes. Nat Methods 7, 200-202.

Hai, A., Shappir, J., and Spira, M.E. (2010b). Long-term, multisite, parallel ,in-cell recording and stimulation by an array of extracellular microelectrodes. J Neurophysiol 104, 559-568.

Harris, K.D., Quiroga, R.Q., Freeman, J., and Smith, S.L. (2016). Improving data quality in neuronal population recordings. Nat Neurosci 19, 1165.1174-

Hermann, J.K., and Capadona, J.R. (2018). Understanding the Role of Innate Immunity in the Response to Intracortical Microelectrodes. Crit Rev Biomed Eng 46, 341-367.

Hong, G., Yang, X., Zhou, T., and Lieber, C.M. (2018). Mesh electronics: a new paradigm for tissuelike brain probes. Curr Opin Neurobiol 50, 33-41.

Horn, R., and Marty, A. (1988). Muscarinic activation of ionic currents measured by a new whole-cell recording method. J Gen Physiol 92, 145-159.

Hrabetova, S., Cognet, L., Rusakov, D.A ,.and Nagerl, U.V. (2018). Unveiling the Extracellular Space of the Brain: From Super-resolved Microstructure to In Vivo Function. J Neurosci 38, 9355-9363.

Huang, S.H., Shmoel, N., Jankowski, M.M., Erez, H., Sharon, A., Abu-Salah, W., Nelken, I., Weiss, A ,.and Spira, M.E. (2020). Immunohistological and Ultrastructural Study of the Inflammatory Response to Perforated Polyimide Cortical Implants: Mechanisms Underlying Deterioration of Electrophysiological Recording Quality. Front Neurosci 14, 926.

Iwanaga ,Y., Braun, D., and Fromherz, P. (2001). No correlation of focal contacts and close adhesion by comparing GFP-vinculin and fluorescence interference of Dil. Eur Biophys J 30, 17-26.

Jackson, A., and Fetz, E.E. (2007). Compact movable microwire array for long-term chronic unit recording in cerebral cortex of primates. J Neurophysiol 98, 3109-3118.

Johnson, M.D., Otto, K.J., and Kipke, D.R. (2005). Repeated voltage biasing improves unit recordings by reducing resistive tissue impedances. IEEE Trans Neural Syst Rehabil Eng 13, 160-165.

Jones, P.D., Moskalyuk, A., Barthold, C., Gutohrlein, K., Heusel, G., Schroppel, B., Samba, R., and Giugliano, M. (2020). Low-Impedance 3D PEDOT:PSS Ultramicroelectrodes. Front Neurosci 14, 405.

Kettenmann, H., Hanisch, U.K ,.Noda, M., and Verkhratsky, A. (2011). Physiology of microglia. Physiol Rev 91, 461-553.

Korogod, N., Petersen, C.C., and Knott, G.W. (2015). Ultrastructural analysis of adult mouse neocortex comparing aldehyde perfusion with cryo fixation. Elife 4.

Kozai ,T.D., Jaquins-Gerstl, A.S., Vazquez, A.L., Michael, A.C., and Cui, X.T. (2015). Brain tissue responses to neural implants impact signal sensitivity and intervention strategies. ACS Chem Neurosci 6, 48-67.

Kozai, T.D., Li, X., Bodily, L.M., Caparosa, E.M ,.Zenonos, G.A., Carlisle, D.L., Friedlander, R.M., and Cui, X.T. (2014). Effects of caspase-1 knockout on chronic neural recording quality and longevity: insight into cellular and molecular mechanisms of the reactive tissue response. Biomaterials 35, 962.0-9634

Lambacher, A., and Fromherz, P. (2002). Luminescence of dye molecules on oxidized silicon and fluorescence interference contrast microscopy of biomembranes. Journal of the Optical Society of America B-Optical Physics 19, 1435-1453.

Lee, H.C., Gaire, J., Roysam, B., and Otto, K.J. (2018). Placing Sites on the Edge of Planar Silicon Microelectrodes Enhances Chronic Recording Functionality. IEEE Trans Biomed Eng 65, 12451255.

Lee, Y., Shin, H., Lee, D., Choi, S., Cho, I.J., and Seo, J. (2021). A Lubricated Nonimmunogenic Neural Probe for Acute Insertion Trauma Minimization and Long-Term Signal Recording. Adv Sci (Weinh), e2100231.

Li, X.L., Mo, J.S., Fang, J.R., Xu, D.X., Yang, C., Zhang, M., Li, H.B., Xie, X., Hu, N., and Liu, F.M. (2020). Vertical nanowire array-based biosensors: device design strategies and biomedical applications. Journal of Materials Chemistry B 8, 7609-7632.

Lin, Z.C., and Cui, B. (2014). Nanowire transistors: room for manoeuvre. Nat Nanotechnol 9, 94-96. 
bioRxiv preprint doi: https://doi.org/10.1101/2021.10.03.461535; this version posted October 4, 2021. The copyright holder for this preprint (which was not certified by peer review) is the author/funder, who has granted bioRxiv a license to display the preprint in perpetuity. It is made available under aCC-BY-NC-ND 4.0 International license.

Lin, Z.C., Xie, C., Osakada, Y., Cui, Y., and Cui, B. (2014). Iridium oxide nanotube electrodes for sensitive and prolonged intracellular measurement of action potentials. Nat Commun 5, 3206.

Liu, R., Chen, R., Elthakeb, A.T., Lee, S.H., Hinckley, S., Khraiche, M.L., Scott, J ,.Pre, D., Hwang, Y., Tanaka, A., Ro, Y.G., Matsushita, A.K., Dai, X., Soci, C., Biesmans, S., James, A., Nogan, J., Jungjohann, K.L., Pete, D.V., Webb, D.B., Zou, Y., Bang, A.G., and Dayeh, S.A. (2017). High Density Individually Addressable Nanowire Arrays Record Intracellular Activity from Primary Rodent and Human Stem Cell Derived Neurons. Nano Letters 17, 2757-2764.

Logothetis, N.K., Kayser, C., and Oeltermann, A. (2007). In vivo measurement of cortical impedance spectrum in monkeys: implications for signal propagation. Neuron 55, 809-823.

Luan, L., Wei, X., Zhao, Z., Siegel, J.J., Potnis, O., Tuppen, C.A., Lin, S., Kazmi, S., Fowler, R.A., Holloway, S., Dunn, A.K., Chitwood, R.A., and Xie, C. (2017). Ultraflexible nanoelectronic probes form reliable ,glial scar-free neural integration. Sci Adv 3, e1601966.

Malaga, K.A., Schroeder, K.E., Patel, P.R., Irwin, Z.T., Thompson, D.E., Nicole Bentley, J., Lempka, S.F., Chestek, C.A., and Patil, P.G. (2016). Data-driven model comparing the effects of glial scarring and interface interactions on chronic neural recordings in non-human primates. J Neural Eng 13, 016010.

Marton, G., Toth, E.Z., Wittner, L., Fiath, R., Pinke, D., Orban, G., Meszena, D., Pal, I., Gyori, E.L., Bereczki, Z., Kandracs, A., Hofer, K.T ,.Pongracz, A., Ulbert, I., and Toth, K. (2020). The neural tissue around SU-8 implants: A quantitative in vivo biocompatibility study. Materials Science \& Engineering C-Materials for Biological Applications 112.

Massobrio, G., Martinoia, S., and Massobrio, P. (2018). Equivalent Circuit of the Neuro-Electronic Junction for Signal Recordings From Planar and Engulfed Micro-Nano-Electrodes. IEEE Trans Biomed Circuits Syst 12, 3-12.

Massobrio, P., Massobrio, G., and Martinoia, S. (2016). Interfacing Cultured Neurons to Microtransducers Arrays: A Review of the Neuro-Electronic Junction Models. Front Neurosci 10, 282.

Mateus, J.C., Lopes, C.D.F., Cerquido, M., Leitao, L., Leitao, D., Cardoso, S., Ventura, J., and Aguiar, P. (2019). Improved in vitro electrophysiology using 3D-structured microelectrode arrays with a micro-mushrooms islets architecture capable of promoting topotaxis. J Neural Eng 16, 036012.

Mccreery, D., Cogan, S., Kane, S., and Pikov, V. (2016). Correlations between histology and neuronal activity recorded by microelectrodes implanted chronically in the cerebral cortex. J Neural Eng 13, 036012.

Mcguire, A.F., Santoro, F., and Cui, B. (2018). Interfacing Cells with Vertical Nanoscale Devices: Applications and Characterization. Annu Rev Anal Chem (Palo Alto Calif) 11, 101-126.

Mercanzini, A., Cheung, K., Buhl, D., Boers, M., Maillard, A., Colin, P., Bensadoun, J.C., Bertsch, A., Carleton, A., and Renaud, P. (2007). Demonstration of cortical recording and reduced inflammatory response using flexible polymer neural probes. Proceedings of the Ieee Twentieth Annual International Conference on Micro Electro Mechanical Systems, Vols 1 and 2, 810.+-

Mercanzini, A., Cheung, K., Buhl, D.L., Boers, M., Maillard, A., Colin, P., Bensadoun, J.C., Bertsch, A ,.and Renaud, P. (2008). Demonstration of cortical recording using novel flexible polymer neural probes. Sensors and Actuators a-Physical 143, 90-96.

Michelson, N.J., Vazquez, A.L., Eles, J.R., Salatino, J.W., Purcell, E.K., Williams, J.J., Cui, X.T., and Kozai, T.D.Y. (2018). Multi-scale, multi-modal analysis uncovers complex relationship at the brain tissue-implant neural interface: new emphasis on the biological interface. J Neural Eng 15, 033001.

Moffitt, M.A., and Mcintyre, C.C. (2005). Model-based analysis of cortical recording with silicon microelectrodes. Clin Neurophysiol 116, 2240-2250.

Moss, J., Ryder, T., Aziz, T.Z., Graeber, M.B., and Bain, P.G. (2004). Electron microscopy of tissue adherent to explanted electrodes in dystonia and Parkinson's disease. Brain 127, 2755-2763.

Nahirney, P.C., and Tremblay, M.E. (2021). Brain Ultrastructure: Putting the Pieces Together. Front Cell Dev Biol 9, 629503.

Ojovan, S.M., Rabieh, N., Shmoel, N., Erez, H., Maydan, E., Cohen, A., and Spira, M.E. (2015). A feasibility study of multi-site,intracellular recordings from mammalian neurons by extracellular gold mushroom-shaped microelectrodes. Sci Rep 5, 14100. 
bioRxiv preprint doi: https://doi.org/10.1101/2021.10.03.461535; this version posted October 4, 2021. The copyright holder for this preprint (which was not certified by peer review) is the author/funder, who has granted bioRxiv a license to display the preprint in perpetuity. It is made available under aCC-BY-NC-ND 4.0 International license.

Otto, K.J., Johnson, M.D., and Kipke, D.R. (2006). Voltage pulses change neural interface properties and improve unit recordings with chronically implanted microelectrodes. IEEE Trans Biomed Eng $53,333-340$.

Perge, J.A., Homer, M.L., Malik, W.Q., Cash, S., Eskandar, E., Friehs, G., Donoghue, J.P., and Hochberg, L.R. (2013). Intra-day signal instabilities affect decoding performance in an intracortical neural interface system. J Neural Eng 10, 036004.

Polikov, V.S., Tresco, P.A., and Reichert, W.M. (2005). Response of brain tissue to chronically implanted neural electrodes. J Neurosci Methods 148, 1-18.

Prasad, A., and Sanchez, J.C. (2012). Quantifying long-term microelectrode array functionality using chronic in vivo impedance testing. J Neural Eng 9, 026028.

Qing, Q., Jiang, Z., Xu, L., Gao, R.X., Mai, L.Q., and Lieber, C.M. (2014). Free-standing kinked nanowire transistor probes for targeted intracellular recording in three dimensions. Nature nanotechnology 9, 142-147.

Quiroga, R.Q., Nadasdy, Z., and Ben-Shaul, Y. (2004). Unsupervised spike detection and sorting with wavelets and superparamagnetic clustering. Neural Comput 16, 1661-1687.

Rabieh, N., Ojovan, S.M., Shmoel, N., Erez, H., Maydan, E., and Spira, M.E. (2016). On-chip, multisite extracellular and intracellular recordings from primary cultured skeletal myotubes. Sci Rep 6, 36498.

Richter, A., Xie, Y., Schumacher, A., Loffler, S., Kirch, R.D., Al-Hasani, J., Rapoport, D.H., Kruse, C., Moser, A., Tronnier, V., Danner, S., and Hofmann, U.G. (2013). A simple implantation method for flexible, multisite microelectrodes into rat brains. Front Neuroeng. 6,6

Robinson, J.T., Jorgolli, M., Shalek, A.K., Yoon, M.H., Gertner, R.S., and Park, H. (2012). Vertical nanowire electrode arrays as a scalable platform for intracellular interfacing to neuronal circuits. Nat Nanotechnol 7, 180-184.

Salatino, J.W., Kale, A.P., and Purcell, E.K. (2019). Alterations in Ion Channel Expression Surrounding Implanted Microelectrode Arrays in the Brain. bioRxiv

Salatino, J.W., Ludwig, K.A., Kozai, T.D.Y., and Purcell, E.K. (2017a). Glial responses to implanted electrodes in the brain. Nature Biomedical Engineering 1, 862-877.

Salatino, J.W., Winter, B.M., Drazin, M.H., and Purcell, E.K. (2017b). Functional remodeling of subtype-specific markers surrounding implanted neuroprostheses. J Neurophysiol 118, 194-202.

Santoro, F ,.Dasgupta, S., Schnitker, J., Auth, T., Neumann, E., Panaitov, G., Gompper, G., and Offenhäusser, A. (2014). Interfacing electrogenic cells with 3D nanoelectrodes: Position, shape, and size matter. ACS Nano 8, 6713-6723.

Santoro, F., Schnitker, J., Panaitov, G., and Offenhäusser, A. (2013). On chip guidance and recording of cardiomyocytes with 3D mushroom-shaped electrodes. Nano Letters 13, 5379-5384.

Santoro, F., Van De Burgt, Y., Keene, S.T., Cui, B.X., and Salleo, A. (2017a). Enhanced Cell-Chip Coupling by Rapid Femtosecond Laser Patterning of Soft PEDOT:PSS Biointerfaces. ACS Appl Mater Interfaces 9, 39116-39121.

Santoro, F., Zhao, W., Joubert, L.M., Duan, L., Schnitker, J., Van De Burgt, Y., Lou, H.Y., Liu, B., Salleo, A., Cui, L., Cui, Y., and Cui, B .(2017b). Revealing the Cell-Material Interface with Nanometer Resolution by Focused Ion Beam/Scanning Electron Microscopy. Acs Nano 11, 83208328.

Savage, J.C., Picard, K., Gonzalez-Ibanez, F., and Tremblay, M.E. (2018). A Brief History of Microglial Ultrastructure: Distinctive Features, Phenotypes, and Functions Discovered Over the Past 60 Years by Electron Microscopy. Front Immunol 9, 803.

Saxena, T., Karumbaiah, L., Gaupp, E.A., Patkar, R., Patil, K., Betancur, M., Stanley, G.B., and Bellamkonda, R.V .(2013).The impact of chronic blood-brain barrier breach on intracortical electrode function. Biomaterials 34, 4703-4713.

Schilling, T., and Eder, C. (2015). Microglial $\mathrm{K}(+)$ channel expression in young adult and aged mice. Glia 63, 664-672.

Schindelin ,J., Arganda-Carreras, I., Frise, E., Kaynig, V., Longair, M., Pietzsch, T., Preibisch, S., Rueden, C., Saalfeld, S., Schmid, B., Tinevez, J.Y., White, D.J., Hartenstein, V., Eliceiri, K., Tomancak, P., and Cardona, A. (2012). Fiji: an open-source platform for biological-image analysis. Nat Methods 9, 676-682. 
bioRxiv preprint doi: https://doi.org/10.1101/2021.10.03.461535; this version posted October 4, 2021. The copyright holder for this preprint (which was not certified by peer review) is the author/funder, who has granted bioRxiv a license to display the preprint in perpetuity. It is made available under aCC-BY-NC-ND 4.0 International license.

Schneider, C.A., Rasband, W.S., and Eliceiri, K.W. (2012). NIH Image to ImageJ: 25 years of image analysis. Nat Methods 9, 671-675.

Schultz, R.L., and Willey, T.J. (1976). Ultrastructure of Sheath around Chronically Implanted Electrodes in Brain. Journal of Neurocytology 5, 621-642.

Sharon, A., Jankowski, M.M., Shmoel, N., Erez, H., and Spira, M.E. (2021). Inflammatory Foreign Body Response Induced by Neuro-Implants in Rat Cortices Depleted of Resident Microglia by a CSF1R Inhibitor and Its Implications. Front Neurosci 15, 646914.

Shmoel, N., Rabieh, N., Ojovan, S.M., Erez, H., Maydan, E., and Spira, M.E. (2016). Multisite electrophysiological recordings by self-assembled loose-patch-like junctions between cultured hippocampal neurons and mushroom-shaped microelectrodes. Sci Rep 6, 27110.

Sommakia, S., Gaire, J., Rickus, J.L., and Otto, K.J. (2014). Resistive and reactive changes to the impedance of intracortical microelectrodes can be mitigated with polyethylene glycol under acute in vitro and in vivo settings. Front Neuroeng 7, 33.

Sommakia, S., Rickus, J.L., and Otto, K.J. (2009). Effects of adsorbed proteins, an antifouling agent and long-duration DC voltage pulses on the impedance of silicon-based neural microelectrodes. Conf Proc IEEE Eng Med Biol Soc 2009, 7139-7142.

Soria, F.N., Miguelez, C., Penagarikano, O., and Tonnesen, J. (2020). Current Techniques for Investigating the Brain Extracellular Space. Front Neurosci 14, 570750.

Spira, M.E., and Hai, A. (2013). Multi-electrode array technologies for neuroscience and cardiology. Nat Nanotechnol 8, 83-94.

Spira, M.E., Huang, S.H., Shmoel, N., and Erez, H. (2019). "In Vitro Neuronal Networks -From Culturing Methods toNeuro-Technological Applications," in Adv Neurobiol, eds. C. M., P. V. \& F. M. 2019/05/11 ed: Springer Nature Switzerland ), 125-153.

Spira, M.E., Kamber, D., Dormann, A., Cohen, A., Bartic, C., Borghs, G., Langedijk, J.P.M., Yitzchaik, S., Shabthai, K., and Shappir, J. (2007). Improved neuronal adhesion to the surface of electronic device by engulfment of protruding micro-nails fabricated on the chip surface. Transducers \& Eurosensors 1, 1247-1250.

Spira, M.E., Shmoel, N., Huang, S.M., and Erez, H. (2018). Multisite Attenuated Intracellular Recordings by Extracellular Multielectrode Arrays, a Perspective. Front Neurosci 12, 212.

Straub, B., Meyer, E., and Fromherz, P. (2001). Recombinant maxi-K channels on transistor, a prototype of iono-electronic interfacing. Nat Biotechnol 19.121-124,

Szarowski, D.H., Andersen, M.D., Retterer, S., Spence, A.J., Isaacson, M., Craighead, H.G., Turner, J.N., and Shain, W. (2003). Brain responses to micro-machined silicon devices. Brain Res 983, 23 35.

Teixeira, H., Dias, C., Aguiar, P., and Ventura, J. (2020). Gold-Mushroom Microelectrode Arrays and the Quest for Intracellular-Like Recordings: Perspectives and Outlooks. Adv Mater Technol 2000770, 1-27.

Thompson, C.H., Riggins, T.E., Patel, P.R., Chestek, C.A., Li, W., and Purcell, E. (2020). Toward guiding principles for the design of biologically-integrated electrodes for the central nervous system. J Neural Eng 17, 021001.

Tian, B., Cohen-Karni, T., Qing, Q., Duan, X., Xie, P., and Lieber, C.M. (2010). Three-dimensional, flexible nanoscale field-effect transistors as localized bioprobes. Science (New York, N.Y.) 329, 830-834.

Tremblay, M.E., Zettel, M.L., Ison, J.R., Allen, P.D., and Majewska, A.K. (2012). Effects of aging and sensory loss on glial cells in mouse visual and auditory cortices. Glia 60, 541-558.

Turner, J.N., Shain, W., Szarowski, D.H., Andersen, M., Martins, S., Isaacson, M., and Craighead, H. (1999). Cerebral astrocyte response to micromachined silicon implants. Exp Neurol 156, 33-49.

Vezzani, A., and Viviani, B. (2015). Neuromodulatory properties of inflammatory cytokines and their impact on neuronal excitability. Neuropharmacology 96, 70-82.

Voigts, J., Siegle, J.H., Pritchett, D.L., and Moore, C.I. (2013). The flexDrive: an ultra-light implant for optical control and highly parallel chronic recording of neuronal ensembles in freely moving mice. Front Syst Neurosci 7, 8.

Wei, X., Luan, L., Zhao, Z., Li, X., Zhu, H., Potnis, O., and Xie, C. (2018). Nanofabricated Ultraflexible Electrode Arrays for High-Density Intracortical Recording. Adv Sci (Weinh) 5, 1700625 . 
bioRxiv preprint doi: https://doi.org/10.1101/2021.10.03.461535; this version posted October 4, 2021. The copyright holder for this preprint (which was not certified by peer review) is the author/funder, who has granted bioRxiv a license to display the preprint in perpetuity. It is made available under aCC-BY-NC-ND 4.0 International license.

Weidlich, S., Krause, K.J., Schnitker, J., Wolfrum, B., and Offenhausser, A. (2017). MEAs and 3D nanoelectrodes: electrodeposition as tool for a precisely controlled nanofabrication. Nanotechnology 28, 095302.

Weis, R ,.and Fromherz, P. (1997). Frequency dependent signal transfer in neuron transistors. Physical Review E 55, 877-889.

Williams, J.C., Hippensteel, J.A., Dilgen, J., Shain, W., and Kipke, D.R. (2007). Complex impedance spectroscopy for monitoring tissue responses to inserted neural implants. J Neural Eng 4, 410-423.

Winslow, B.D., Christensen, M.B., Yang, W.K., Solzbacher, F., and Tresco, P.A. (2010). A comparison of the tissue response to chronically implanted Parylene-C-coated and uncoated planar silicon microelectrode arrays in rat cortex. Biomaterials 31, 9163-9172.

Winslow, B.D., and Tresco, P.A. (2010). Quantitative analysis of the tissue response to chronically implanted microwire electrodes in rat cortex. Biomaterials 31, 1558-1567.

Wrobel, G., Holler, M., Ingebrandt, S., Dieluweit, S., Sommerhage, F., Bochem, H.P., and Offenhausser, A. (2008). Transmission electron microscopy study of the cell-sensor interface. $J R$ Soc Interface 5, 213-222.

Xiang, Z.L., Yen, S.C., Xue, N., Sun, T., Tsang, W.M., Zhang, S.S., Liao, L.D., Thakor, N.V., and Lee, C. (2014). Ultra-thin flexible polyimide neural probe embedded in a dissolvable maltosecoated microneedle. Journal of Micromechanics and Microengineering 24.

Xie, C., Lin, Z., Hanson, L., Cui, Y., and Cui, B .(2012) .Intracellular recording of action potentials by nanopillar electroporation. Nat Nanotechnol 7, 185-190.

Xie, Y., Martini, N., Hassler, C., Kirch, R.D., Stieglitz, T., Seifert, A., and Hofmann, U.G. (2014). In vivo monitoring of glial scar proliferation on chronically implanted neural electrodes by fiber optical coherence tomography. Front Neuroeng 7, 34.

Xu, D., Mo, J., Xie, X., and Hu, N. (2021). In-Cell Nanoelectronics: Opening the Door to Intracellular Electrophysiology. Nanomicro Lett 13, 127.

Yang, X., Zhou, T., Zwang, T.J., Hong, G., Zhao, Y., Viveros, R.D., Fu, T.M., Gao, T., and Lieber, C.M. (2019). Bioinspired neuron-like electronics. Nat Mater 18, 510-517.

Yoo, J., Kwak, H., Kwon, J., Ha, G.E., Lee, E.H., Song, S., Na, J., Lee, H.J., Lee ,J., Hwangbo, A., Cha, E., Chae, Y., Cheong, E., and Choi, H.J. (2020). Long-term Intracellular Recording of Optogenetically-induced Electrical Activities using Vertical Nanowire Multi Electrode Array. Scientific Reports 10.

Zhang, A., Lee, J.H., and Lieber, C.M. (2021). Nanowire-enabled bioelectronics. Nano Today 38, 117.

Zhao, W., Hanson, L., Lou, H.Y., Akamatsu, M., Chowdary, P.D., Santoro, F., Marks, J.R., Grassart, A., Drubin, D.G., Cui, Y., and Cui, B. (2017). Nanoscale manipulation of membrane curvature for probing endocytosis in live cells. Nat Nanotechnol 12, 750-756.

Zhou, T., Hong, G., Fu, T.M., Yang, X., Schuhmann, T.G., Viveros, R.D., and Lieber, C.M. (2017). Syringe-injectable mesh electronics integrate seamlessly with minimal chronic immune response in the brain. Proc Natl Acad Sci U S A 114, 5894-5899. 


\section{Figure captions}
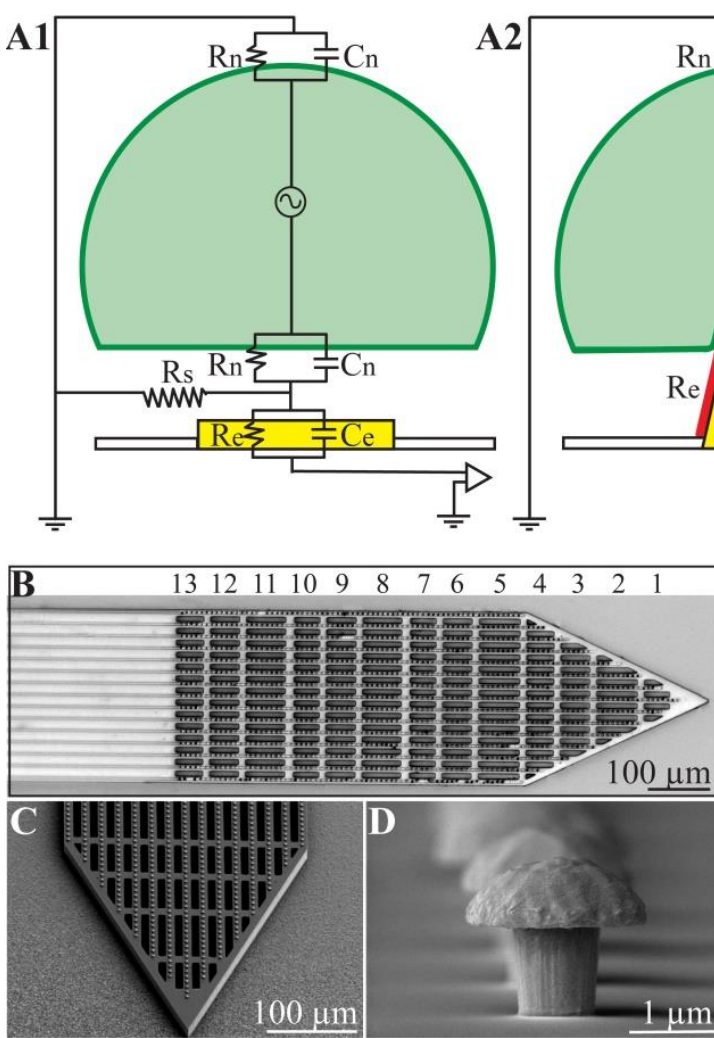
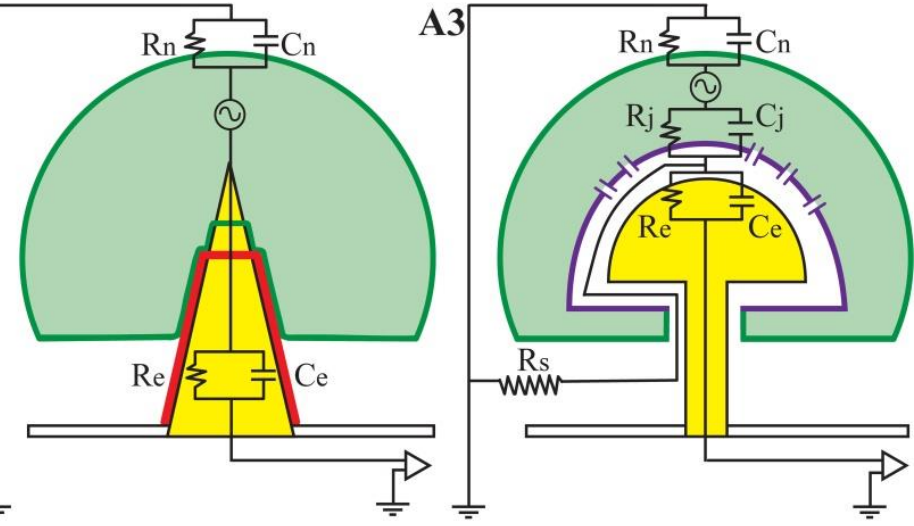

$\mathbf{E}$
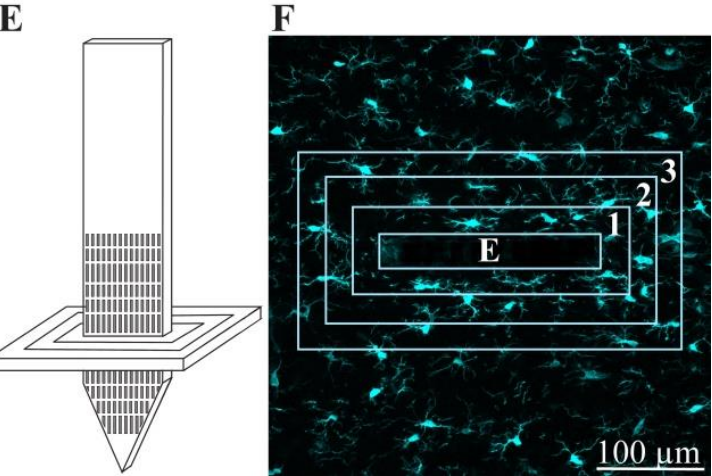

Figure 1. (A) Passive analog electrical circuit models depicting the structural interfaces formed between cells and recording microelectrodes under in-vitro conditions. (A1) substrate integrated planar electrode for extracellular field potential recordings, (A2) a vertical nanopillar electrode that pierces the plasma membrane for intracellular recordings, and (A3), extracellular gold mushroom shaped vertical microelectrode $(\mathrm{gM} \mu \mathrm{E})$ for IN-CELL recordings. The three configurations differ mainly in terms of the nature and dimensions of the cleft formed between the cultured cells (neurons, cardiomyocytes or striated muscle fibers) and the recording electrode. In (A1), the extracellular field potential generated by propagating action potentials is largely attenuated across the high resistance non-junctional membrane ( $\mathrm{Rn})$ and the low seal resistance (Rs). In (A2), the vertical nanoelectrode pierces the cell's plasma membrane, gaining direct access to the cytosol ( $\mathrm{Rn}$ is reduced to zero). A very high seal $(\sim \mathrm{G} \Omega)$ resistance (not drawn) formed between the vertical nanoelectrode's (yellow electrode with a red insulating layer) surface and the plasma membrane (green). In (A3), the cell engulfs a mushroom shaped vertical electrode (yellow) to form relatively high Rs by the narrow cleft. Along with reduced junctional membrane resistance ( $\mathrm{Rj}$-purple) the configuration makes it possible to record attenuated intracellular potentials. (B) Low magnification image of the polyimide based perforated MEA platform (PPMP), the proximal solid part and distal perforated part are shown. For orientation, the rows of perforations are numbered. (C) SEM enlargement of a PPMP segment, showing the perforations of the polyimide platform and dense rows of gM $\mu$ Es along the PI "ribs". (D) A SEM image of a $\mathrm{gM \mu E}$. (E) Schematic illustration of an implanted PPMP and the orientation of thick horizontal tissue slices. (F) The integrated immuno-fluorescent intensity within the electrode (central rectangle- E) and within $25 \mu \mathrm{m}$ wide centripetal shells around it were measured and processed to establish the normalized fluorescent intensity level (NFI) or the number of a given cell type at a given distance and time around the implant. 

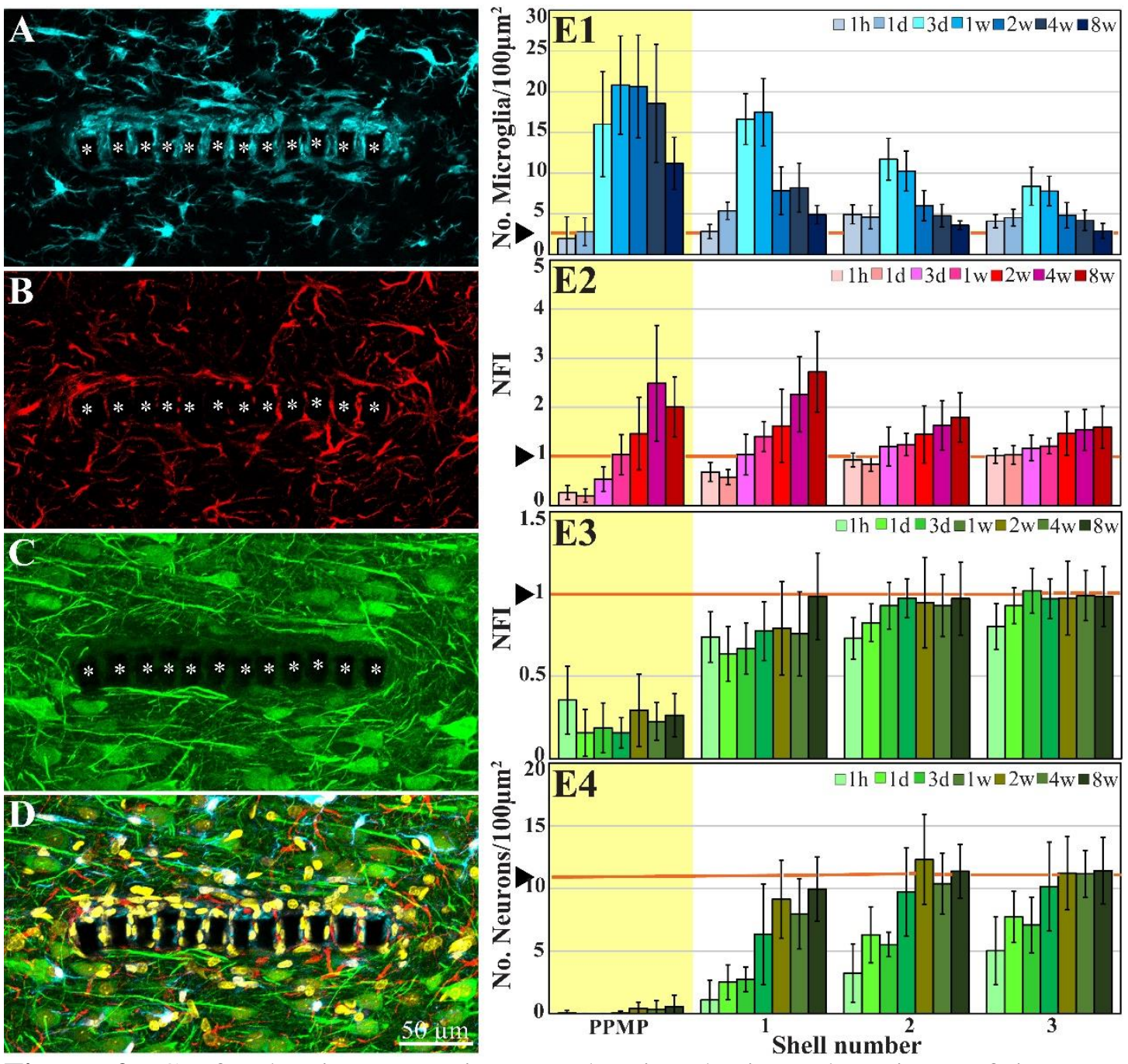

Figure 2. Confocal microscope images showing horizontal-sections of immuno-labeled cortical brain tissue along with cross sections of the perforated segment of an implanted PPMP, two weeks post implantation. Shown are: microglia (cyan) within and around the implant marked by asterisks (A), astrocytes ( $\mathrm{B}$, red), neurons and neurites (C, green), and a merged image of (A-C) which also includes the nuclei of the cells labeled in yellow (D). (E) Histograms depicting the average Normalized Fluorescent Intensity (NFI) or number of cells $/ 100 \mu \mathrm{m}^{2}$. Microglia (E1, cyan), astrocytes (E2, red), neurites and cell bodies (E3, green) and neuronal cell bodies (E4, green) within and around the platform's perforated segments. The time post-platform implantation is coded by the darkening of the column color as indicated by the legend on the right hand side of the histograms. The average NFI values or the cells $/ 100 \mu \mathrm{m}^{2}$ within the platforms (PPMP) are highlighted in yellow. The distance of the average NFI from the MEA platform is given by shell number. Each shell is $25 \mu \mathrm{m}$ wide (as illustrated in Figure 1F). Vertical lines correspond to one standard deviation. The orange lines indicated by the arrowheads depict the normal NFI values or the number of cell/100 $\mu \mathrm{m} 2$ in the control cortices. An enlarged image of D is presented as Supplementary Figure S2. 


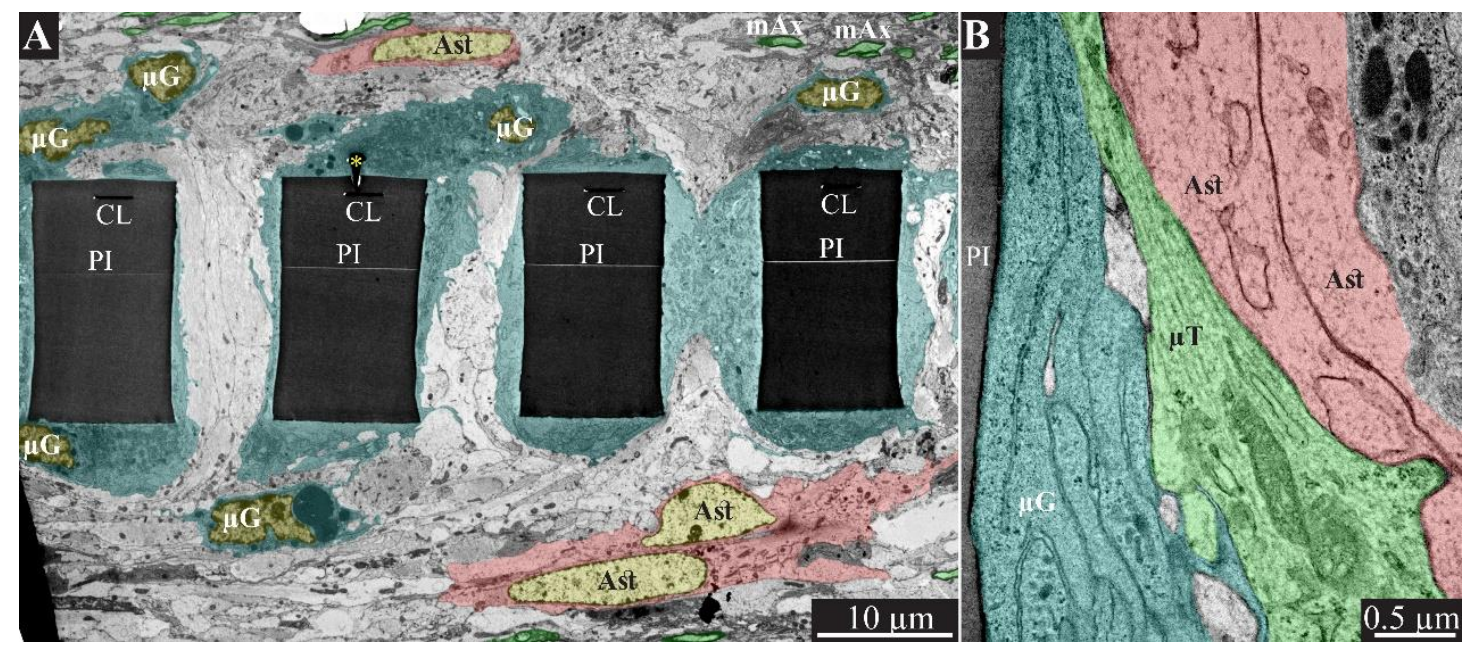

Figure 3. Encapsulation of individual PPMPs "ribs" by adhering microglia. (A) A low magnification transmission electron microscope cross-section of an implanted PPMP along with the parenchyma around it 2 weeks after platform implantation. The PI "ribs" are encompassed by microglia (cytoplasm marked in cyan and typical microglia nuclei $\mu \mathrm{G}$ yellow) and astrocytes (cytoplasm marked pink, and astrocyte nuclei Ast- yellow). (B) Microglia adhering to the PI surface interposed between the implant and non-myelinated neurites containing microtubules and astrocyte branches that invaded the platform pores. No myelinated axons were seen in the immediate vicinity of the implant at this point in time after PPMP implantation. PI- polyimide ribs, $\mathrm{gM} \mu \mathrm{E}-$ yellow asterisks, $\mathrm{mAx}$ - myelinated axons (green), CL -conducting line, $\mu \mathrm{G}$ - microglia, $\mu \mathrm{T}$ - microtubule, Ast- astrocyte. Note that an unmarked copy of this figure is presented as Supplementary Figure S3.

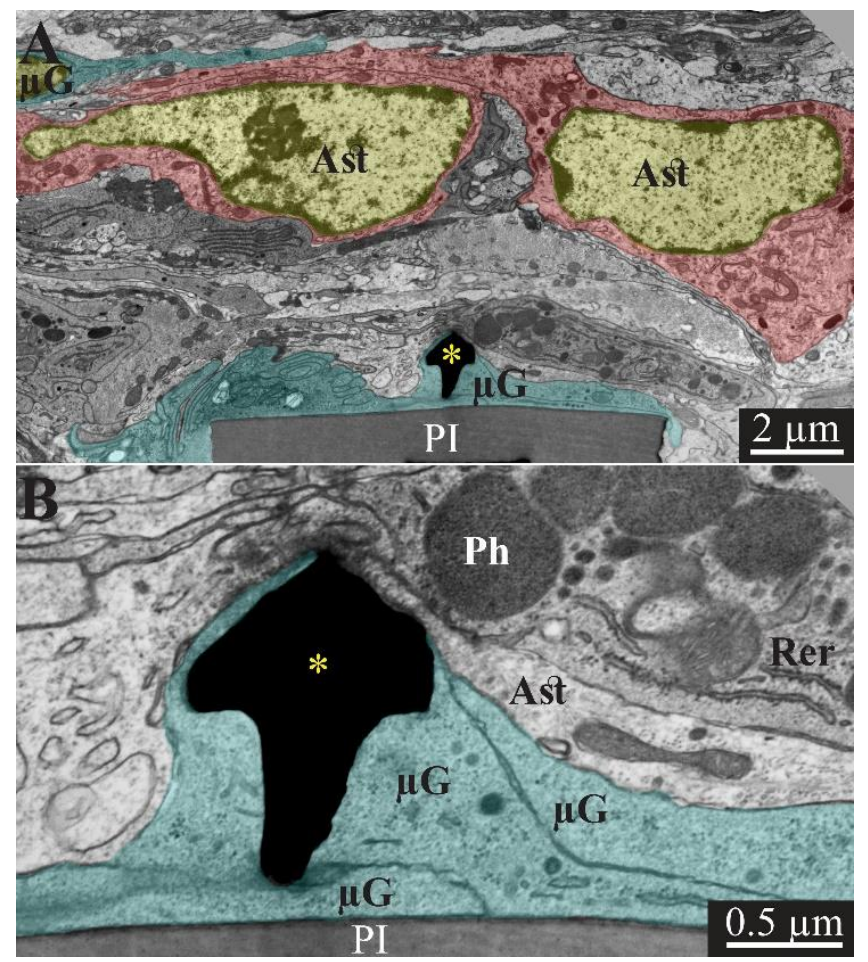

Figure 4. Transmission electron microscope images of a $\mathrm{gM \mu E}$ (black mushroom shaped profiles A, B) tightly engulfed by microglia, 2 weeks after PPMP implantation. Note the thin 0.5-1 $\mu \mathrm{m}$ layers of microglia branches that adhered tightly to the PI surface and the gold mushroom microelectrode (cyan). Additional microglia layers characterized by dark cytoplasm (not labeled in color) contained a rough endoplasmic reticulum and dark inclusions 
bioRxiv preprint doi: https://doi.org/10.1101/2021.10.03.461535; this version posted October 4, 2021. The copyright holder for this preprint (which was not certified by peer review) is the author/funder, who has granted bioRxiv a license to display the preprint in perpetuity. It is made available under aCC-BY-NC-ND 4.0 International license.

which plausibly were lysosomes and lipofuscine granules. Astrocyte branches characterized by sparse electron dense material containing intermediate filaments invaded in between the microglia branches but did not form direct contact with the implant. Note that the TEM section is slightly tilted in respect to the long axis of the $\mathrm{gM} \mu \mathrm{E}$. For that reason the mushroom's stalk appears to taper toward the polyimide platform and looks like it end in the tissue rather than attached to polyimide. Astrocyte cell bodies resided micrometers away from the implant. PI- polyimide ribs, $\mathrm{gM} \mu \mathrm{E}$ - yellow asterisks, $\mu \mathrm{G}$ - microglia, Rer- rough endoplasmic reticulum, Ast- astrocyte. An unmarked copy of this figure is presented as Supplementary Figure S4.
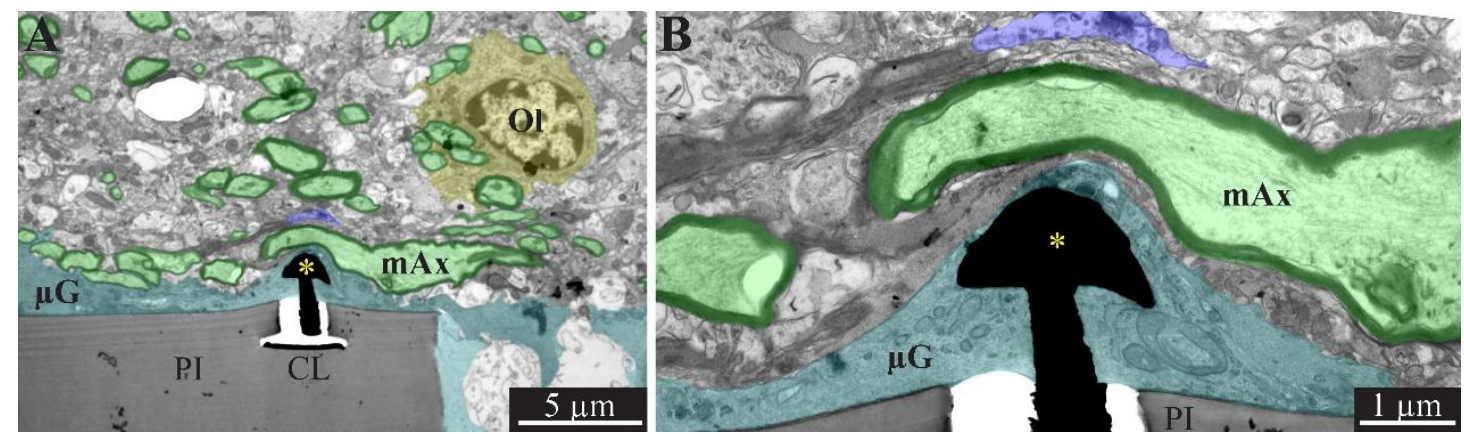

Figure 5. A low and high magnification, transmission electron microscope image of the interfaces formed between a gold mushroom shaped microelectrode extending from a polyimide platform implanted for 4 weeks and the surrounding cortical tissue. The mushroom shaped microelectrode (black) immerges from the PI substrate (gray). Note the thin layer of dark microglia (cyan in A and B, and unmarked dark gray branches in B) adheres tightly to the $\mathrm{gM \mu E}$ and PI substrate. The parenchyma around the implant underwent regenerative processes as indicated by the large number of myelinated axons (green and black envelope) and the presence of oligodendrocytes in the immediate vicinity of the implant (yellow). Whereas axonal branches with a relatively large diameter $(\sim 3 \mu \mathrm{m})$ extended close to the $\mathrm{gM} \mu \mathrm{E}$, it is conceivable that the adhering microglia (and in this instance the myelin as well) insulated the electrode from the surrounding excitable tissue. PI- polyimide ribs, CLconducting line, gM $\mu \mathrm{E}$ - yellow asterisks, Ol- oligodendrocyte, $\mu \mathrm{G}$ - microglia, $\mathrm{mAx}$ myelinated axons. Note an unmarked copy of this figure is presented as Supplementary Figure S6. 


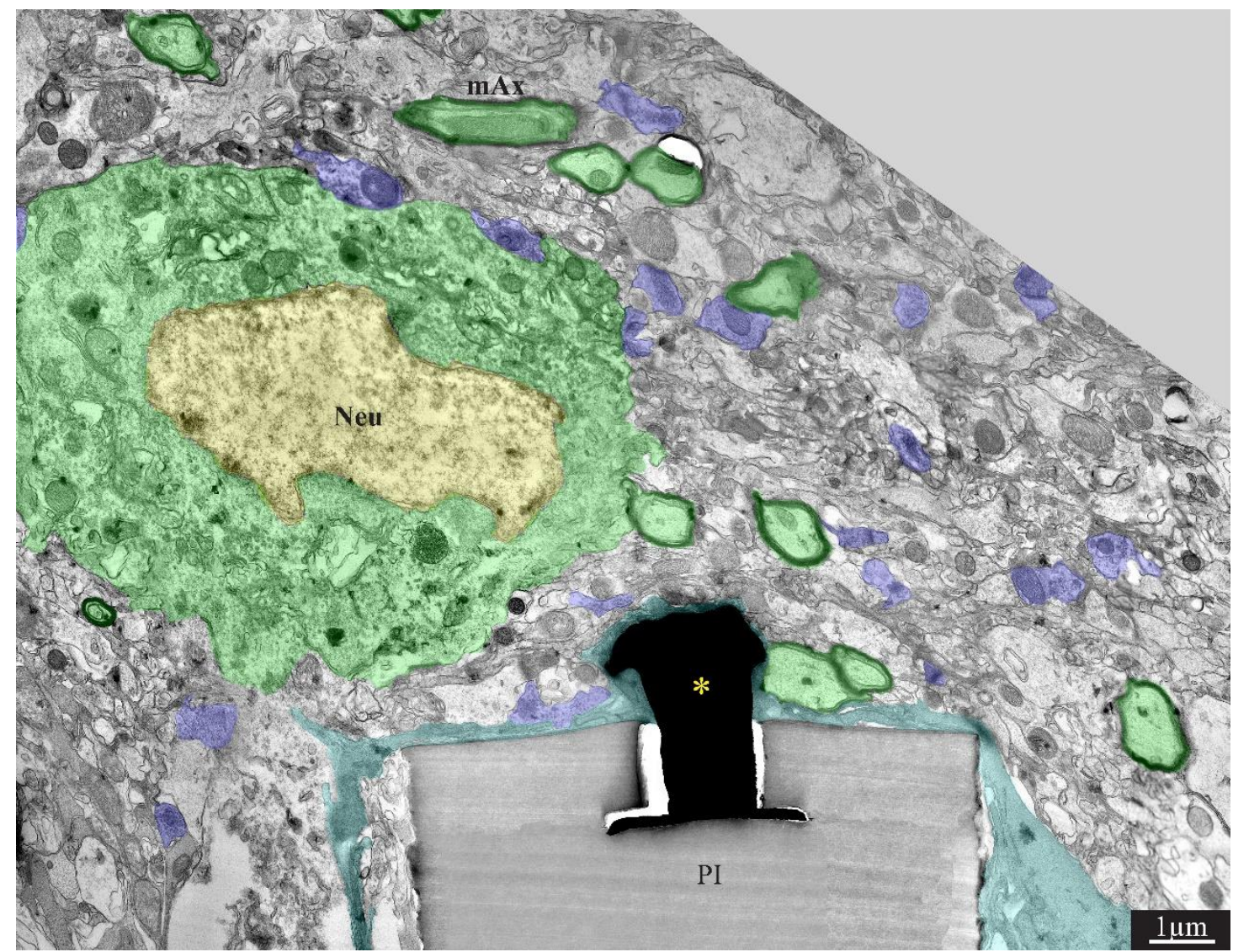

Figure 6. A low magnification, transmission electron microscope image of the interfaces formed between a gold mushroom shaped microelectrode extending from a polyimide platform implanted for 8 weeks and the surrounding cortical tissue. The mushroom shaped microelectrode (black) immerges from the PI substrate (gray). A thin layer of dark microglia (cyan) adheres tightly to the $\mathrm{gM} \mu \mathrm{E}$ and the PI substrate. A neuronal cell body with a typical nuclear structure (yellow) and cytoplasm (green) resides approximately a micrometer away from the $\mathrm{gM} \mu \mathrm{E}$ and the PI platform's surface. Myelinated axons (green surrounded by a black sheath) are distributed in the parenchyma in contact with the microglia that adheres to the platform. Unmyelinated neurites and synaptic structures (labeled purple) were identified (using large magnification of the image) by the presence of presynaptic vesicles. The remainder of the unmarked profiles are astrocyte branches and non-myelinated neurites. PIpolyimide ribs, gM $\mu$ E- yellow asterisks, Neu- neuron, $\mathrm{mAx}$ - myelinated axons. Note that an unmarked copy of this figure is presented as Supplementary Figure S7. 

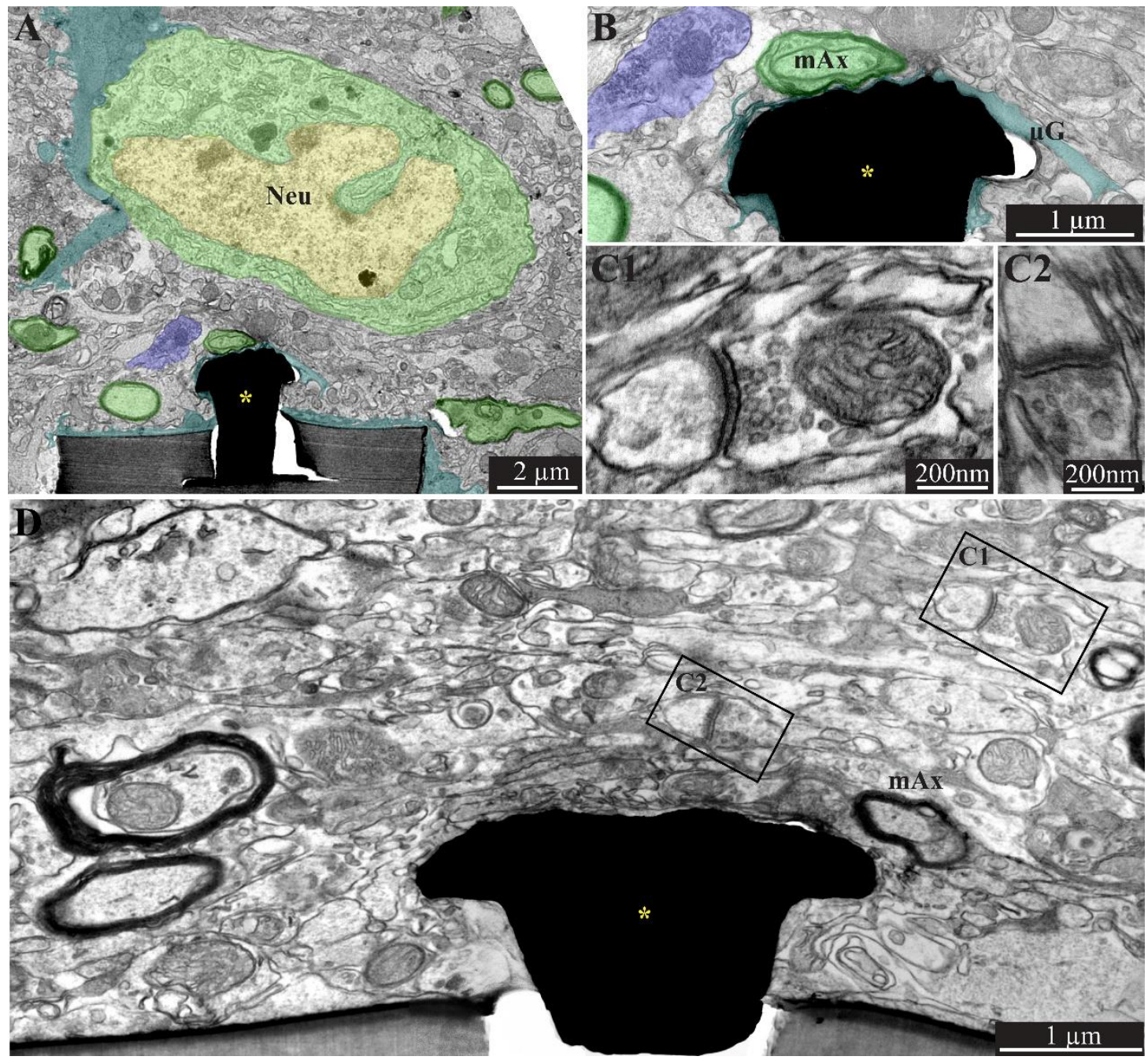

Figure 7. A low (A) and high magnification (B), transmission electron microscope image of the interfaces formed between a gold mushroom shaped microelectrode extending from a polyimide platform implanted for 8 weeks and the surrounding cortical tissue. As the regenerative processes of the brain parenchyma proceed with time, the dark microglia adhering layer becomes thinner (A and B, cyan). It is conceivable that even a thin microglia layer might insulate the electrodes from the surrounding parenchyma. (D) The regenerative processes of the parenchyma are also evidenced by the presence of a chemical synaptic profile as close as a few micrometers from the implant $(\mathrm{C} 1$ and $\mathrm{C} 2$, see $\mathrm{D}$ for the location of the synapses with respect to the electrode). Note that the TEM section (in D) is slightly tilted in respect to the long axis of the $\mathrm{gM} \mu \mathrm{E}$. For that reason the base of the mushrooms stalk appears to taper towards the polyimide platform. Interestingly, eight weeks after implantation we also observed $\mathrm{gM} \mu \mathrm{E}$ that were not enwrapped by microglia and formed a direct contact with the small profile of astrocyte and possibly neurons (D). gM $\mu \mathrm{E}$ - yellow asterisks, Neu- neuron, mAx-myelinated axons, $\mu \mathrm{G}$ - microglia. An unmarked copy of this figure is presented as Supplementary Figure S8. 


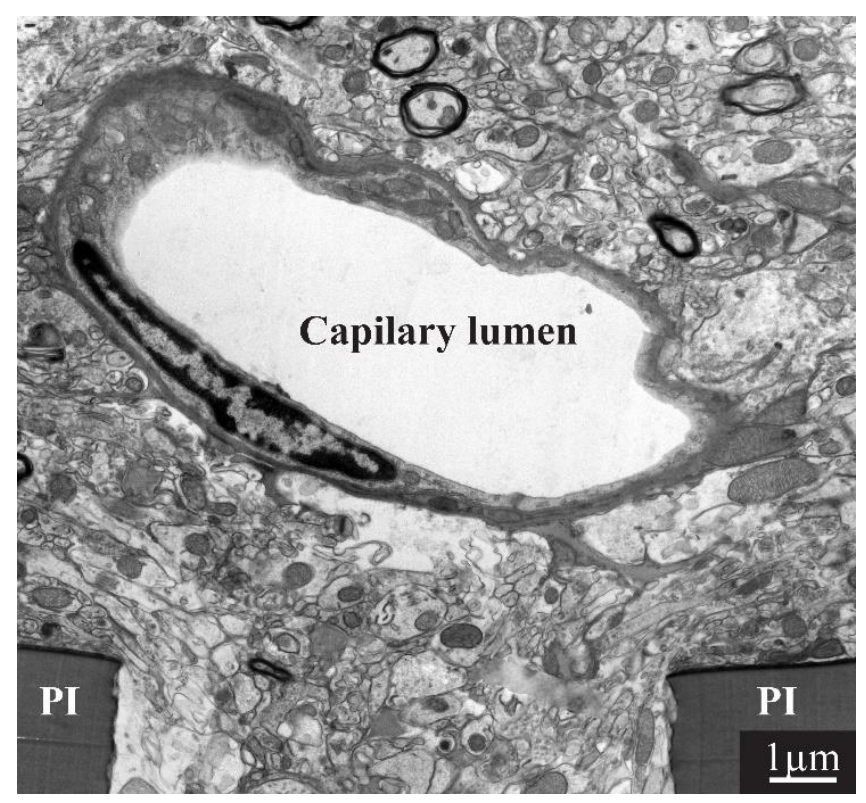

Figure 8. Regeneration of capillaries close to implanted PPMPs. A capillary located micrometers away from the surface of the polyimide (PI) "ribs" of an implanted PPMP for 8 weeks. 